\title{
Osteochondral Tissue Regeneration using a Bilayered Composite Hydrogel with Modulating Dual Growth Factor Release Kinetics in a Rabbit Model
}

\author{
Kyobum Kim ${ }^{a}$, Johnny Lam ${ }^{a}$, Steven Lu ${ }^{a}$, Patrick P. Spicera, Aline Lueckgen ${ }^{a}$, Yasuhiko \\ Tabata $^{\mathrm{b}}$, Mark E. Wong ${ }^{\mathrm{c}}$, John A. Jansen ${ }^{\mathrm{d}}$, Antonios G. Mikos ${ }^{\mathrm{a}}$, and F. Kurtis Kasper ${ }^{\mathrm{a},{ }^{*}}$ \\ aDepartment of Bioengineering, Rice University, Houston, TX bepartment of Biomaterials, \\ Institute for Frontier Medical Sciences, Kyoto University, Kyoto, Japan 'Department of Surgery, \\ Division of Oral and Maxillofacial Surgery, The University of Texas School of Dentistry at \\ Houston, Houston, TX ${ }^{\mathrm{d} D e p a r t m e n t}$ of Biomaterials, Radboud University, Nijmegen Medical \\ Center, Nijmegen, The Netherlands
}

\begin{abstract}
Biodegradable oligo(poly(ethylene glycol) fumarate) (OPF) composite hydrogels have been investigated for the delivery of growth factors (GFs) with the aid of gelatin microparticles (GMPs) and stem cell populations for osteochondral tissue regeneration. In this study, a bilayered OPF composite hydrogel that mimics the distinctive hierarchical structure of native osteochondral tissue was utilized to investigate the effect of transforming growth factor- $\beta 3$ (TGF- $\beta 3$ ) with varying release kinetics and/or insulin-like growth factor-1 (IGF-1) on osteochondral tissue regeneration in a rabbit full-thickness osteochondral defect model. The four groups investigated included (i) a blank control (no GFs), (ii) GMP-loaded IGF-1 alone, (iii) GMP-loaded IGF-1 and gel-loaded TGF- $\beta 3$, and (iv) GMP-loaded IGF-1 and GMP-loaded TGF- $\beta 3$ in OPF composite hydrogels. The results of an in vitro release study demonstrated that TGF- $\beta 3$ release kinetics could be modulated by the GF incorporation method. At 12 weeks post-implantation, the quality of tissue repair in both chondral and subchondral layers was analyzed based on quantitative histological scoring. All groups incorporating GFs resulted in a significant improvement in cartilage morphology compared to the control. Single delivery of IGF-1 showed higher scores in subchondral bone morphology as well as chondrocyte and glycosaminoglycan amount in adjacent cartilage tissue when compared to a dual delivery of IGF-1 and TGF- $\beta 3$, independent of the TGF$\beta 3$ release kinetics. The results suggest that although the dual delivery of TGF- $\beta 3$ and IGF-1 may not synergistically enhance the quality of engineered tissue, the delivery of IGF-1 alone from bilayered composite hydrogels positively affects osteochondral tissue repair and holds promise for osteochondral tissue engineering applications.
\end{abstract}

\section{Keywords}

Hydrogel; osteochondral defect; transforming growth factor- $\beta 3$; insulin-like growth factor- 1

(C) 2013 Elsevier B.V. All rights reserved.

*Corresponding Author: F. Kurtis Kasper, Ph.D., Faculty Fellow, Department of Bioengineering, Rice University, P.O. Box 1892, MS-142, Houston, Texas, 77251-1892, w: 713348 3027, f: 713348 4244, kasper@rice.edu.

Publisher's Disclaimer: This is a PDF file of an unedited manuscript that has been accepted for publication. As a service to our customers we are providing this early version of the manuscript. The manuscript will undergo copyediting, typesetting, and review of the resulting proof before it is published in its final citable form. Please note that during the production process errors may be discovered which could affect the content, and all legal disclaimers that apply to the journal pertain. 


\section{Introduction}

Articular cartilage is a flexible connective tissue that facilitates the articulation of bone in major synovial joints via the dissipation of friction and physiological compressive forces [15]. With a limited endogenous ability for self-repair, damaged cartilage as a result of disease or trauma oftentimes leads to premature arthritis. Although current clinical methods are insufficient for long-term treatment [6], tissue engineering strategies provide promising alternatives for cartilage repair. To date, many research groups have adapted a wide variety of natural or synthetic polymers for the fabrication of scaffolds for cartilage tissue engineering. In particular, hydrogel scaffolds derived from these materials can be used as a vehicle to deliver biochemical factors that stimulate the chondrogenic differentiation of host progenitor cells within a tissue defect site [7,8]. Our laboratory has developed a novel class of water-soluble synthetic macromers based on oligo(poly(ethylene glycol) fumarate) (OPF) that can be chemically crosslinked to yield hydrolytically degradable hydrogels. Injectable and biodegradable hydrogels formed from OPF have been leveraged for the controlled delivery of chondrogenic growth factors (GFs) with the aid of gelatin microparticles (GMPs), which serve as GF delivery vehicles and enzymatically digestible porogens [9-16]. Previously, such composite hydrogel systems have been utilized to deliver chondrogenic GFs for the elicitation of osteochondral tissue repair within osteochondral defect sites in animal models [17-19]. However, the simultaneous delivery of multiple GFs and how these GFs interact in vivo to repair osteochondral tissue remains an area of investigation.

In the present work, OPF composite hydrogels are used to deliver transforming growth factor- $\beta 3$ (TGF- $\beta 3$ ) and/or insulin-like growth factor-1 (IGF-1) to an osteochondral defect to facilitate cartilage regeneration and subchondral tissue formation. TGF- $\beta 3$ is a potent GF that can induce the chondrogenic differentiation of progenitor cell populations in vitro [2023] as well as augment cartilage tissue formation in vivo [24-27]. IGF-1 primarily acts as an anabolic maturation factor to stimulate the cellular synthesis of proteoglycans and type II collagen $[28,29]$. Previously, OPF composite systems were employed to deliver TGF- $\beta 1$, an isoform of TGF- $\beta 3$ with similar chondrogenic effects, to the chondral space of an osteochondral defect [18]. Although the presence of TGF- $\beta 1$ alone did confer some therapeutic advantage, such as the improvement of joint surface regularity over controls at 4 and 14 weeks, the GF did not effect a different overall healing response when compared to controls [18]. To achieve an overall improvement in osteochondral regeneration and to study the effects of a dual GF delivery system in a wound healing environment, the delivery of TGF- $\beta 1$ with IGF-1 on osteochondral tissue repair was evaluated [19]. This study was based on results in literature demonstrating the synergistic effects of TGF- $\beta 1$ with IGF-1 on increased chondrogenic gene expression and proteoglycan synthesis by articular chondrocytes [30, 31] and mesenchymal stem cells (MSCs) in vitro [32]. The in vivo study however, showed that an initial burst release of TGF- $\beta 1$ during early stages of cartilage healing followed by a sustained release of IGF-1 was not effective at regenerating osteochondral tissue under the conditions investigated [19]. Despite the lack of synergy between TGF- $\beta 1$ and IGF-1, the controlled delivery of multiple GFs merits further investigation when one considers the complex interplay of GFs during different stages chondrogenesis and cartilage regeneration [33-35]. Indeed, several in vitro studies have demonstrated that the anabolic effects of TGF- $\beta$ isoforms on progenitor cells are dependent on the time of delivery $[36,37]$. Recently, it was shown that the sequential exposure of umbilical cord-derived MSCs to TGF- $\beta 3$ followed by IGF-1 enhanced their production of cartilage-like extracellular matrix (ECM) components in vitro [38]. Moreover, our laboratory has found that the TGF- $\beta 3$ isoform was more effective than TGF- $\beta 1$ at inducing the chondrogenic differentiation of rabbit MSCs encapsulated within bilayered OPF composite hydrogels [9]. Therefore, we hypothesize that the delivery of TGF- $\beta 3$, when 
combined with the sustained release of IGF-1, may influence the differentiation of host progenitor cell populations and thereby affect the degree of osteochondral tissue repair.

It has been demonstrated that release kinetics of GFs from OPF composite hydrogels can be modulated by hydrogel construction parameters, which include the degree of crosslinking of GMPs, the molecular weight of the poly(ethylene glycol) block in the OPF macromer, the resultant mesh size of such crosslinked OPF hydrogels, and the method of GF incorporation within the composite hydrogel $[11,12,18,19]$. Such a level of tunability with OPF composite hydrogels may be leveraged for the timed delivery of multiple chondrogenic GFs to progenitor cell populations in the host tissues to repair an osteochondral defect. Indeed, the release kinetics of TGF- $\beta 3$ when delivered together with IGF-1 from OPF composite hydrogels might be an important parameter to regulate for the induction of high quality cartilage tissue remodeling and regeneration in vivo. The present study investigates how different release kinetics of TGF- $\beta 3$, in the presence of IGF-1, from OPF composite hydrogels affect the tissue response in an osteochondral defect.

The global hypothesis of this study is that the release of TGF- $\beta 3$, when combined with the sustained release of IGF-1, from OPF composite hydrogels will synergistically facilitate osteochondral tissue regeneration in a rabbit osteochondral defect model relative to the delivery of IGF-1 alone. Furthermore, it is hypothesized that the release kinetics of TGF- $\beta 3$, when delivered together with a sustained release of IGF-1, will influence the degree and quality of osteochondral tissue repair. To this end, the specific objectives of this study are: (1) to characterize the in vitro release kinetics of IGF-1 and TGF- $\beta 3$ from composite hydrogels over 28 days, (2) to investigate the synergistic effect of a dual delivery of TGF- $\beta 3$ with IGF-1 on osteochondral tissue regeneration, and (3) to evaluate the effect of modulated TGF- $\beta 3$ release kinetics with sustained IGF-1 release on the quality of cartilage and subchondral bone tissue regeneration in a rabbit full-thickness osteochondral defect model.

\section{Materials and Methods OPF synthesis}

According to a method developed in our laboratory [39, 40], poly(ethylene glycol) with a number average molecular weight $\left(\mathrm{M}_{\mathrm{n}}\right)$ of 35,000 (Sigma-Aldrich, St. Louis, $\mathrm{MO}$ ) was utilized to synthesize OPF. The resulting OPF with an $\mathrm{M}_{n}$ of 42,500 \pm 180 and a weight average molecular weight $\left(\mathrm{M}_{\mathrm{w}}\right)$ of 120,300 $\pm 6,500$ was used throughout the study. Prior to hydrogel fabrication, OPF was sterilized by exposure to ethylene oxide (EO) for $12 \mathrm{hrs}$ according to established methods [15-17].

\section{Gelatin microparticle fabrication}

Gelatin microparticles (GMPs) were fabricated using acidic gelatin with an isoelectric point of 5.0 (Nitta Gelatin INC., Osaka, Japan) and were crosslinked with 10 or $40 \mathrm{mM}$ glutaraldehyde (Sigma-Aldrich, St. Louis, MO) according to previously established methods [12]. After lyophilization, GMPs with a diameter of $50-100 \mu \mathrm{m}$ were selected by sieving and sterilized with EO prior to hydrogel fabrication. Sterile GMPs were swollen with phosphate buffered saline (PBS) or GF solutions at $4{ }^{\circ} \mathrm{C}$ for $15 \mathrm{hrs}$, according to previously described methods [11]. For equilibrium swelling of GMPs, $55 \mu \mathrm{L}$ of PBS or GF solution was applied to $11 \mathrm{mg}$ of dried GMPs. For the degradation study, blank GMPs were swollen with PBS alone. For the in vitro release study and in vivo implantation, $40 \mathrm{mM}$ GMPs were loaded with an IGF-1 solution with a concentration of $24.42 \mu \mathrm{g}$ of human recombinant IGF-1 (R\&D Systems, Minneapolis, MN) per mL PBS to achieve a concentration of 2000 ng IGF-1 per $\mathrm{mL}$ crosslinked OPF composite hydrogel prior to equilibrium swelling. Similarly, $10 \mathrm{mM}$ GMPs were loaded with a TGF- $\beta 3$ solution with a concentration of 21.97 
$\mu \mathrm{g}$ of human recombinant TGF- $\beta 3$ (R\&D Systems) per mL PBS to achieve $1800 \mathrm{ng}$ TGF- $\beta 3$ per $\mathrm{mL}$ crosslinked OPF composite hydrogel prior to equilibrium swelling. 10 and $40 \mathrm{mM}$ GMPs, which have different degradation rates, were selected to deliver dual GFs in a fashion that first induces chondrogenic differentiation of progenitor cells by TGF- $\beta 3$, followed by IGF-1 induced stimulation of the ECM production [19]. Furthermore, a 2.5 times higher concentration for both IGF- 1 and TGF- $\beta 3$ solutions was used in the preparation of additional groups for the in vitro release study.

\section{Bilayered composite hydrogel fabrication}

Bilayered composite hydrogels to deliver GFs were fabricated via a two-step crosslinking procedure as previously described $[9,10,19]$. The subchondral layer was partially crosslinked first and the chondral layer was fabricated on top of the subchondral layer. Specifically, $100 \mathrm{mg}$ of sterile OPF and $50 \mathrm{mg}$ of sterile poly(ethylene glycol) diacrylate (PEG-DA, Glycosan, Alameda, CA) with a molecular weight of 3400 were dissolved in 468 $\mu \mathrm{L}$ PBS and mixed with $110 \mu \mathrm{L}$ of blank GMPs swollen with PBS (GMP/PBS). Equal parts $(46.8 \mu \mathrm{L})$ of the thermal radical initiators, $0.3 \mathrm{M}$ of ammonium persulfate (APS, SigmaAldrich) and 0.3 M of N,N,N',N'-tetramethylethylenediamine (TEMED, Sigma-Aldrich), were then mixed into the polymer solution. The polymeric mixture was quickly injected into a cylindrical Teflon mold ( $2.2 \mathrm{~mm}$ in diameter and $2.2 \mathrm{~mm}$ in thickness) and partially crosslinked at $37^{\circ} \mathrm{C}$ for $4 \mathrm{~min}$. Subsequently, the polymer-GMP mixture for the chondral layer was prepared. $100 \mathrm{mg}$ of sterile OPF and $50 \mathrm{mg}$ of sterile PEG-DA were dissolved in $468 \mu \mathrm{L}$ PBS and mixed with $110 \mu \mathrm{L}$ of blank GMP solution swollen with PBS for the control group, $55 \mu \mathrm{L}$ of GMP/PBS and $55 \mu \mathrm{L}$ of GMP solution swollen with IGF-1 (GMP/ IGF-1) for Group 1, and $55 \mu \mathrm{L}$ of GMP/IGF-1 and $55 \mu \mathrm{L}$ of GMP solution swollen with TGF- $\beta 3$ (GMP/TGF- $\beta 3$ ) for Group 3 (Table 1). For Group 2 (Gel phase loading), the same amount of OPF/PEG-DA was dissolved in $413 \mu \mathrm{L}$ PBS, mixed with $55 \mu \mathrm{L}$ of TGF- $\beta 3$ solution, and subsequently mixed with $46.8 \mu \mathrm{L}$ of $0.3 \mathrm{M}$ of APS and $46.8 \mu \mathrm{L}$ of $0.3 \mathrm{M}$ of TEMED. The mixture for the chondral layer was then injected onto the partially crosslinked subchondral layer, and crosslinked at $37^{\circ} \mathrm{C}$ for $8 \mathrm{~min}$.

\section{Degradation}

For the swelling and degradation studies, two different sizes of bilayered composite hydrogels containing only GMP/PBS for both chondral and subchondral layers were fabricated as described above. The composite hydrogels were placed in either $3 \mathrm{~mL}$ of PBS or collagenase-PBS (370 ng collagenase 1A per mL PBS) in a 12 well plate, and incubated at $37^{\circ} \mathrm{C}$ for 28 days on a shaker table (70 RPM). At days $1,4,7,14,21$, and 28 , the swelling ratio, sol fraction, and mass remaining for OPF hydrogel composites were determined $(n=4)$ using the following equations; swelling ratio $=\left(\mathrm{W}_{\mathrm{s}}-\mathrm{W}_{\mathrm{d}}\right) / \mathrm{W}_{\mathrm{d}}, \%$ sol fraction $=\left(\mathrm{W}_{\mathrm{i}}-\mathrm{W}_{\mathrm{d}}\right) /$ $\mathrm{W}_{\mathrm{i}} \times 100(\%)$, and mass remaining $=\mathrm{W}_{\mathrm{d}} / \mathrm{W}_{\mathrm{i}} \times 100(\%)$, where $\mathrm{W}_{\mathrm{i}}, \mathrm{W}_{\mathrm{s}}$, and $\mathrm{W}_{\mathrm{d}}$ represent the weight of dried hydrogel immediately after fabrication prior to swelling, the weight of wet hydrogel after swelling at each time point, and the weight of dried hydrogel after swelling at each time point, respectively.

\section{Quantification of in vitro release kinetics}

Release kinetics of the total amount of GFs from bilayered composite hydrogels was assessed by measuring the radioactivity of ${ }^{125}$ I-labeled GFs $[12,18]$. Briefly, ${ }^{125}$ I-labeled IGF-1 and TGF- $\beta 3$ (Perkin Elmer Life Sciences, Boston, MA) were incorporated with unlabeled GFs (Peprotech, Rocky Hill, NJ) for GMP swelling. 3\% of the required GF solution volume for GMP swelling was replaced with ${ }^{125}$ I-labeled GF solution of the same concentration. Bilayered OPF composite hydrogels were fabricated as described above. For the IGF-1 release study, $40 \mathrm{mM}$ GMPs were loaded with ${ }^{125}$ I-labeled IGF-1 and unlabeled IGF-1 for the hydrogels in all groups, while unlabeled TGF- $\beta 3$ was used for hydrogel 
samples in Group 2 (Gel phase loading) and Group 3 (GMP loading) (Table 1). For the TGF- $\beta 3$ release study, $10 \mathrm{mM}$ GMPs were loaded with ${ }^{125}$ I-labeled TGF- $\beta 3$ and unlabeled TGF- $\beta 3$ in the presence of unlabeled IGF-1 was used for the samples in Group 2 (Gel phase loading) and Group 3 (GMP loading). In addition, a 2.5 times higher GF amount (i.e., 2.5 times higher concentration of GF solution with same volume for GMP swelling or gel phase loading) was loaded in hydrogels to investigate the effect of GF concentration on release kinetics. After fabrication, hydrogels were placed in $3 \mathrm{~mL}$ of PBS or collagenase-PBS in a 12 well plate, and incubated at $37^{\circ} \mathrm{C}$ for 28 days on a shaker table ( $\left.70 \mathrm{RPM}\right)$. At $2 \mathrm{hrs}, 12$ hrs, days 1, 2, 4, 7, 10, 14, 18,21, 24, and 28, the supernatant of each hydrogel was collected and replaced with fresh buffer solution. The amount of released GF was determined by the correlation of measured radioactivity to a standard curve using a gamma counter (Cobra II Autogamma, Packard, Meridian, CT) ( $\mathrm{n}=5$ ).

\section{Bioactivity of released growth factors}

Release kinetics of biologically active GFs were assessed by cellular assays, as described in previous studies [41, 42]. Bilayered composite hydrogels $3 \mathrm{~mm}$ in diameter and $3 \mathrm{~mm}$ in thickness were utilized. For the IGF-1 activity assay, hydrogels in Group 1 were fabricated as described above. Hydrogels delivering both IGF-1 and TGF- $\beta 3$ were not examined with the cellular assays, as the presence of TGF- $\beta 3$ may confound the results. Four hydrogels were placed in $1 \mathrm{~mL}$ of collagenase-PBS in a 12 well plate, and incubated at $37^{\circ} \mathrm{C}$ for 28 days on a shaker table (70 RPM). At 2 hrs, 12 hrs, days 1, 2, 4, 7, 10, 14, 18, 21, 24, and 28, the supernatant of each hydrogel was collected and replaced with fresh buffer solution. Collected supernatants were stored at $-80^{\circ} \mathrm{C}$ until the assay time. A MCF-7 cell line proliferation assay was used to measure the biologically active fraction of released IGF-1 from the composite hydrogels [42]. 5,000 MCF-7 cells (HBT-22, ATCC, Manassas, VA) in serum-free DMEM:F12 medium (Life Technologies, Grand Island, NY) were plated in a 96 well plate. $25 \mu \mathrm{L}$ of collected supernatant or $25 \mu \mathrm{L}$ of an IGF-1 standard $(0.15-20 \mathrm{ng} / \mathrm{mL}$ range) were then added. The cells were cultured in an incubator $\left(37^{\circ} \mathrm{C}, 5 \% \mathrm{CO}_{2}\right)$ for $72 \mathrm{hrs}$. Proliferative activity of plated cells was measured by a CellTiter Blue assay (Promega, Madison, WI) according to the manufacturer's protocol. Fluorescence intensity was measured using a microplate reader (excitation $560 \mathrm{~nm} /$ emission $590 \mathrm{~nm}$ ). A standard curve was generated by a 4 parameter fit and the active amount of released IGF- 1 was calculated at each time point $(n=4)$ [42]. The cumulative $\%$ active release was plotted based on the released amount of IGF-1 as measured with ${ }^{125}$ I-labeled GFs in the "Quantification of in vitro release kinetics" section. For the TGF- $\beta 3$ activity assay, composite hydrogels in Group 2 and Group 3 were fabricated as described above. Similarly, IGF-1 was not included in these composite hydrogels as its presence may confound the results of the TGF- $\beta 3$ activity assay. Three gels in each group were placed in $1 \mathrm{~mL}$ of collagenase-PBS in a 12 well plate, and incubated at $37^{\circ} \mathrm{C}$ for 28 da ys on a shaker table (70 RPM). Sample collection and storage were the same as described above. A Mink lung epithelial cell line (CCL-64, ATCC, Manassas, VA) inhibition assay was used to measure the biologically active fraction of released TGF- $\beta 3$ from OPF composites [41]. 10,000 CCL-64 cells (HBT-22, ATCC, Manassas, VA) in DMEM media (Life Technologies, Grand Island, NY) were plated in a 96 well plate. $25 \mu \mathrm{L}$ of collected supernatant or $25 \mu \mathrm{L}$ of a TGF- $\beta 3$ standard $(0.005-5 \mathrm{ng} / \mathrm{mL}$ range) were then added. The cells were cultured in an incubator $\left(37^{\circ} \mathrm{C}, 5 \% \mathrm{CO}_{2}\right)$ for $72 \mathrm{hrs}$. The level of inhibition, the active amount of released TGF- $\beta 3$, and the cumulative $\%$ release of active TGF- $\beta 3$ were analyzed as described above.

\section{Animal surgery}

A total of 24 skeletally mature (i.e., 6 months old) male New Zealand white rabbits were utilized in this study based on a previously established full-thickness osteochondral defect model [17-19]. The number of defects and animals per each group were determined by 
power analysis and consideration of previous studies [17-19]. All surgical procedures were approved by the Institutional Animal Care and Use Committees of Rice University and University of Texas Health Science Center at Houston. Animal surgeries for implantation in bilateral defects were performed as previously described [17-19]. Prior to surgery, anesthesia was induced by subcutaneous injection of Ketamine $(25-40 \mathrm{mg} / \mathrm{kg}$ ) and Acepromazine (1-2 mg/kg). General anesthesia was then maintained through ventilator administration of a mixture of isoflurane and oxygen. Osteochondral defects $(3 \mathrm{~mm}$ in diameter and $3 \mathrm{~mm}$ in thickness) were created on the medial femoral condyles. Prefabricated bilayered composite hydrogels were swollen in sterile PBS for 30 minutes and these swollen composite hydrogels with the same dimensions as the defect were press-fitted into the osteochondral defect. Then, the muscle and skin were closed. This procedure was repeated for the contralateral knee using a hydrogel of the same formulation. Therefore, each animal received two hydrogels (one per knee) and a total of 12 hydrogels $(n=12)$ were implanted in 6 animals per experimental group. To minimize postoperative discomfort, Carprofen $(4 \mathrm{mg} / \mathrm{kg})$ was administrated for 2 days post-operatively.

\section{Tissue Processing}

Rabbits were euthanized by intravenous administration of Beuthanasia $(0.22 \mathrm{~mL} / \mathrm{kg})$ at 12 weeks post-surgery. The tissue surrounding the medial femoral condyle was retrieved en bloc, fixed in $10 \%$ buffered formalin $(\mathrm{pH} 7.4)$ for 1 week, decalcified in EDTA solution for 6 weeks, dehydrated through a graded series of ethanol baths, and then embedded in paraffin. Longitudinal sections of $6 \mu \mathrm{m}$ thickness were taken from the center (within the central $1 \mathrm{~mm}$ ), lateral edge (within the lateral $1 \mathrm{~mm}$ ), and medial edge (within the medial 1 $\mathrm{mm}$ ) of each defect using a microtome. Two sections from each location were stained with hematoxylin and eosin (H\&E), Safranin O/Fast Green, and van Gieson's Picrofuchsin.

\section{Histological Scoring}

Histological sections were blindly and independently scored by three evaluators (J.L., P.P.S., and F.K.K.) using a previously established scoring system for osteochondral repair, as shown in Table 2 [17]. A total of 11 parameters to evaluate osteochondral repair were used to analyze the whole defect for both chondral (within the upper $1 \mathrm{~mm}$ of the defect) and subchondral (within the bottom $2 \mathrm{~mm}$ of the defect) regions.

\section{Statistical Analysis}

The data from the in vitro assays were analyzed by one-way analysis of variance (ANOVA) and Turkey's multiple-comparison test. The means and the standard deviations were reported in each figure. For the histological analysis, ordered logistic regression of histological scores was performed to analyze the potential effect of experimental group, location within the defect, and knee joint [17-19]. $\mathrm{p}<0.05$ was considered to indicate a significant difference.

\section{Results}

\section{Degradation of bilayered OPF composite hydrogels}

The swelling ratio of bilayered OPF composite hydrogels remained stable over 28 days in PBS, but started to increase after 7 days in collagenase-PBS (Fig 1A). The sol fraction of composite hydrogels in PBS was also stable (about 40\%) over 28 days (Fig 1B). However, the sol fraction in collagenase-PBS started to increase after 7 days of incubation and maintained a gradual increase until day 28. Similarly, the fraction of the initial mass remaining continuously decreased over time in collagenase-PBS (Fig 1C). 


\section{In vitro IGF-1 release kinetics}

The $\%$ cumulative release profiles of IGF-1 (as measured by radiolabeled IGF-1) over 28 days for Groups 1-3 are shown in Fig 2A - 2C, respectively, while the \% cumulative release profile of the active amount of released IGF-1 for Group 1 (as measured by cellular assays) is shown in Fig 2D. The release kinetics of IGF-1 were similar between groups in both PBS and collagenase-PBS conditions as seen in Fig $2 \mathrm{~A}-2 \mathrm{C}$. Initial burst release of IGF-1 within the first 4 days in collagenase-PBS was $43.9 \pm 3.4 \%$ in Group 1 (GMP-loaded IGF-1 only), $46.2 \pm 1.7 \%$ in Group 2 (GMP-loaded IGF-1 and gel-loaded TGF- $\beta 3$ ), and $40.8 \pm 3.7 \%$ in Group 3 (GMP-loaded IGF-1 and GMP-loaded TGF- $\beta 3$ ). 28-day \% cumulative IGF-1 release in collagenase PBS was $83.2 \pm 1.4 \%$ in Group 1, $85.0 \pm 0.9 \%$ in Group 2, and 85.2 $\pm 3.0 \%$ in Group 3. In addition, the IGF-1 release rate (\% release of IGF-1 per day) is shown in Table 3A. No statistical difference was observed between groups in collagenasePBS during all phases. For all groups, approximately $30 \%$ of IGF- 1 was released in phase 1 (up to $24 \mathrm{hrs}$ ), while approximately $1 \%$ of IGF-1 was released each day in phase 4 (days 18 -28) (Table 3A). Biologically active IGF-1 released from the OPF composites (i.e., the released IGF-1 to actively enhance the proliferation of the MCF-7 cell line) was analyzed by using the same formulation in Group 1 in collagenase-PBS. Fig 2D showed that $36.6 \pm 8.8$ $\%$ of active IGF- 1 was released within the first 4 days and that a total cumulative release of $66.6 \pm 15.5 \%$ was achieved by day 28 . Release rate of active IGF-1 in collagenase-PBS (Table 3B) was similar to release rate determined by gamma counter (Table 3A) in all phases.

\section{In vitro TGF- $\beta 3$ release kinetics}

The $\%$ cumulative release profile of TGF- $\beta 3$ over 28 days is shown in Fig $3 \mathrm{~A}$ and $3 \mathrm{~B}$, while the $\%$ cumulative release profile of the active amount of TGF- $\beta 3$ is shown in Fig $3 \mathrm{C}$. When comparing Group 2 and Group 3, a significantly higher burst release of TGF- $\beta 3$ is seen within the first 2 days in Group 2 in collagenase-PBS (Fig 3A). Specifically, the 2-day burst release of TGF- $\beta 3$ is $26.4 \pm 3.3 \%$ in Group 2 (GMP-loaded IGF-1 and gel-loaded TGF- $\beta 3$ ) and $19.5 \pm 3.5 \%$ in Group 3 (GMP-loaded IGF- 1 and GMP-loaded TGF- $\beta 3$ ), although the 4-day release for both groups has no statistical difference (32.2 $\pm 3.3 \%$ in Group 2 and 36.5 $\pm 4.0 \%$ in Group 3). From day 7 to day 28 , the $\%$ cumulative release is higher in Group 3 than in Group 2 at each time point (Fig 3A). The 28-day \% cumulative TGF- $\beta 3$ release in collagenase-PBS is $71.4 \pm 9.2 \%$ in Group 2 and $84.8 \pm 2.6 \%$ in Group 3. Similar release kinetics were found in the standard PBS condition (Fig 3B). The release rate of TGF- $\beta 3$ (\% release per day) in Table 4A also indicates the difference between Groups 2 and 3. The release rate in Group 2 is higher than that in Group 3 in phase 1, but the release rate in Group 3 is higher than that in Group 2 in phases 2 and 3 in collagenase-PBS. The release of a higher (2.5 times) concentration of TGF- $\beta 3$ in composite hydrogels featured similar $\%$ cumulative release profiles and the release rate (data not shown).

Biologically active released TGF- $\beta 3$ (i.e., the released TGF- $\beta 3$ to actively inhibit the proliferation of the CCL-64 cell line) was analyzed by using the same formulations for Groups 2 and 3 (Fig 3C) in collagenase-PBS. Initial burst release of active TGF- $\beta 3$ as measured by a cell assay is similar within the first 2 days for both formulations. The 28-day $\%$ cumulative release of active TGF- $\beta 3$ is $58.4 \pm 11.9 \%$ in Group 2 and $69.0 \pm 18.6 \%$ in Group 3. The release rate of active TGF- $\beta 3$ in Group 3 is higher than that in Group 2 for phases 2 and 3 from days 1 to 18 (Table 4B).

\section{Histological observation and scoring}

Sections from three locations (lateral edge, medial edge, and center) per sample were obtained for histological evaluation. Representative images from each group are shown in 
Fig $4-7$, respectively. Fig 8 shows the histological scores for the 11 parameters listed in Table 2.

In all groups, partially degraded OPF gels were observed in the subchondral layer (Fig 4 7). No significant difference was observed in both overall tissue filling and overall hydrogel degradation (Fig 8A). In all formulations, a mean score of about 2 was recorded in overall filling at the 12 week time point. This observation was closely related to a mean score of 2 in the percent degradation of the implant. Partially degraded gels in the subchondral layer in all formulations contributed to this score. In addition, statistical analysis revealed that location in the defect (lateral/medial/center) was a significant factor in overall degradation. Specifically, degradation in the lateral edge was greater than that in the center, which is correlated with the observation of remaining hydrogel in the center area.

Although mean scores for overall hydrogel degradation in Fig 8A are similar in all groups, none of the samples in the control group (Fig 4), which lacked GF incorporation, showed complete degradation, while groups incorporating GF showed at least one sample with complete degradation (i.e., all three sections per sample with a score of 3; one sample in Group 1, one in Group 2, and two in Group 3). In particular, the size of partially degraded gels in the subchondral region in Group 1 was generally smaller than those found in the control (i.e., approximately less than $30 \%$ of subchondral area in all sections), as shown in Fig 5. Specimens in groups delivering both IGF-1 and TGF- $\beta 3$ (Groups 2 and 3) showed similar subchondral characteristics to samples seen in the control group, such as the frequency of partially degraded gels, the presence of inflammatory cells, and the area covered with newly formed bone tissues in the defect site (Fig 6E and 7E).

In the evaluations for subchondral bone regeneration including percent bone filling, bone morphology, and bonding between newly formed bone tissue and adjacent bone (Table 2), the mean score for bone filling was slightly above 2 (Fig 8B) in all groups. However, the frequency of complete bone filling in Group 1 is greater than the other groups (data not shown). Although inflammatory cells and surrounding fibrous tissue were also observed in samples from Group 1 (Fig 5E), the quality and frequency of trabecular bone formation was higher than the specimens in the control group. Location in the defect was also a significant factor in bone filling; scores for the lateral edge were significantly higher than those for the center.

In subchondral bone morphology, a mean score $(1.67 \pm 0.96)$ for Group 1 (GMP-loaded IGF-1 only) was higher than that $(1.11 \pm 0.62)$ for Group 3 (GMP-loaded IGF-1 and GMPloaded TGF- $\beta 3$ ). In the blank control, the morphological characteristics of newly formed subchondral tissue in the defect were generally a mixture of compact bone with fibrous tissues (Fig 4 and 9A). As indicated by the score distribution in Fig 9A, sections in Group 1 showed higher levels of trabecular bone regeneration as well as less compact bone with fibrous tissue formation than other groups. However, the presence of partially degraded OPF gels that were surrounded by fibrous tissues maintained a mean score between 1 and 2 for each group. Despite this result, bone bonding between newly formed tissue and adjacent native bone within the subchondral region was found to be complete on both edges of the defect and received a score of 3 for all sections in all experimental groups (Fig 8B).

Cartilage regeneration was evaluated in the categories of cartilage morphology, thickness of newly formed cartilage, surface regularity, chondrocyte clustering, chondrocyte and glycosaminoglycan (GAG) amount in newly formed cartilage, and chondrocyte and GAG amount in adjacent cartilage tissue (Table 2). Histological analysis of the cartilage region indicated that the formulation significantly affected the cartilage morphology as well as the cell and GAG content in adjacent cartilage tissue (Fig 8C). However, location (lateral/ 
medial/center) within the defect was not a significant factor. For cartilage morphology, all GF groups (Group 1, 2, and 3) received statistically higher mean scores when compared to the blank control (without GF loading). The score distribution for cartilage morphology (Fig 9B) indicated that higher levels of hyaline cartilage regeneration as well as less fibrous tissue formation were more frequent in Groups 1,2, and 3 than the blank control. The cartilage layer in samples in the control group (Fig 4) was usually composed of thick fibrous tissue and fibrocartilage and the complete disruption of neo-cartilage surface or deep fissures in the cartilage layer was also observed in some samples. Neo-cartilage tissue in the chondral layer in GF groups (Fig 5-7) was usually fibrocartilage (Fig 9B). However, it should be noted that the frequency of hyaline cartilage accompanied with a smooth surface and zonal organization was higher in GF groups than the control (Fig 9C). Group 2 (GMPloaded IGF-1 and gel-loaded TGF- $\beta 3$ ) received the highest mean score $(2.17 \pm 0.61)$ (Fig 8C) and frequency of hyaline-like cartilage tissue formation (Fig 9B), which indicated the presence of a mixture of newly formed hyaline cartilage and fibrocartilage within the cartilage defect space. Samples with hyaline cartilage formation generally demonstrated intensive GAG staining and less chondrocyte clustering, as shown in Fig 6D. Overall cartilage morphology observed in Group 3 was similar to that in Group 2, except with less GAG staining (Fig 7B and 7D).

Although no statistical differences were observed in cartilage thickness, surface regularity, and chondrocyte clustering (Fig 8C), all GF incorporating groups (Groups 1, 2, and 3) received higher mean scores for these parameters than the blank control. Mean scores for surface regularity (between 1 and 2) and chondrocyte clustering (around 1) reflected that newly formed cartilage tissues in all formulations contained some fissures and clustered chondrocyte populations, respectively. Scores for cell and GAG amount in neo-cartilage did not show any statistical difference between groups (Fig 8C). In cell and GAG amount in adjacent cartilage tissue, normal chondrocyte cellularity and normal Safranin O staining (i.e., a mean score close to 3) were observed for all formulations. Specifically, the mean score $(3.00 \pm 0.00)$ in Group 1 (GMP-loaded IGF-1 only) for this parameter was statistically higher than that $(2.75 \pm 0.50)$ in Group 2 (GMP-loaded IGF-1 and gel-loaded TGF- $\beta 3$ ).

\section{Discussion}

The main objective of this study was to determine the effect of dual GF delivery using IGF-1 and TGF- $\beta 3$ in bilayered OPF composite hydrogels for osteochondral tissue regeneration. Specifically, we investigated (1) how the in vitro release kinetics of TGF- $\beta 3$ could be modulated by differing the incorporation method in OPF composite hydrogels, in the presence of IGF-1, (2) whether the delivery of TGF- $\beta 3$ in the presence of IGF- 1 would enhance the osteochondral tissue regeneration over delivery of IGF-1 alone, and (3) whether varied release kinetics of TGF- $\beta 3$ when delivered with IGF- 1 would affect the degree of osteochondral tissue regeneration in a rabbit defect model. While we have previously studied the effects of TGF- $\beta 1$ delivery alone and the dual delivery of TGF- $\beta 1$ and IGF- 1 in a rabbit osteochondral model $[18,19]$, questions regarding how interactions between multiple GFs and how varying the release kinetics of these GFs affect osteochondral tissue regeneration in vivo remain to be investigated.

An increase in GF release (Fig 2 and 3), especially in phase 3 (Day 4-18) was related to GMP degradation by collagenase and subsequent mass loss (Fig 1). The release profile demonstrated that the release kinetics of IGF-1 were not influenced by the incorporation of the other GF (i.e., TGF- $\beta 3$ ) in the same layer of a bilayered hydrogel construct, while the release kinetics of TGF- $\beta 3$ could be modulated by loading the GF in the GMP or OPF phase of the hydrogel composites (Fig 2, 3 and Tables 3,4). In addition, the release kinetics of TGF- $\beta 3$ were not influenced by the concentration of GF solution used to swell the GMPs. It 
was hypothesized that the ionic complexation of GFs with GMPs would reduce any loss of their activity [43]. Indeed, higher amounts of active TGF- $\beta 3$ released were detected in Group 3 (GMP-loaded TGF- $\beta 3$ ) compared to Group 2 (gel-loaded TGF- $\beta 3$ ) using a Mink lung epithelial cell line, especially in phase 2 and 3 (Table 4).

Histological data demonstrated that improved cartilage morphology in the defect by GF incorporation was observed when compared to the control (Fig 8C), indicating a beneficial effect of GF delivery (TGF- $\beta 3$ and/or IGF-1) using OPF composite hydrogels. The released bioactive GFs may have contributed to the migration of host cell populations to the defect site, stimulated the chondrogenic differentiation of progenitor stem cells, and subsequently improved cartilage-like tissue regeneration. Histological data also demonstrated that TGF- $\beta 3$ delivery in the presence of IGF-1 (specifically, Group 2) resulted in a greater frequency of hyaline-like cartilage formation (Fig 8C and 9B). No major degenerative effect on surrounding host tissues was observed throughout the samples in the dual delivery groups (i.e., Group 2 and 3). Highly localized TGF- $\beta 3$ delivery in the present study did not influence fibrous tissue formation in both chondral and subchondral layers when histological sections in Group 2 and 3 were compared to those in the blank control. Although a higher frequency of hyaline cartilage formation (Fig 9B) was observed in Group 2, any synergistic effect of dual GF delivery of TGF- $\beta 3$ with IGF-1 over a single delivery of IGF-1 was limited. Both dual GF delivery groups (i.e., Group 2 and 3) did not show higher levels of osteochondral tissue regeneration over delivery of IGF-1 alone (Fig 8C). The significant differences between GF loading groups were found in bone morphology (Fig 8B) and adjacent GAG (Fig 8C). Delivery of IGF-1 alone (Group 1) showed an improved subchondral bone morphology over Group 3 (GMP-loaded IGF-1 and GMP-loaded TGF- $\beta 3$ ) as well as a higher cell and GAG amount in adjacent cartilage tissue over Group 2 (GMPloaded IGF-1 and gel-loaded TGF- $\beta 3$ ).

These results show that delivery of IGF-1 alone for osteochondral tissue repair improves the subchondral bone morphology and the interaction with the surrounding chondral tissue over a dual GF delivery with IGF- 1 and TGF- $\beta 3$. Since TGF- $\beta 3$ has been shown to have an inhibitory effect on the osteogenic differentiation of MSCs and osteoblastic cells in vitro [9, $44,45]$, it is possible that the amount of TGF- $\beta 3$ released in this study suppressed subchondral bone formation. Indeed, greater amounts of active TGF- $\beta 3$ were released in Group 3 as compared to Group 2, potentially resulting in the significantly lower bone morphology score observed in Group 3 than in Group 1. Further research could help elucidate the effects of TGF- $\beta 3$ on in vivo subchondral bone repair. Additionally, other in vivo studies using the dual delivery of IGF- 1 and TGF- $\beta 1$ in a rabbit full-thickness defect model for osteochondral tissue regeneration also demonstrated a lack of synergy despite the fact that different hydrogel materials and different types and doses of GF were applied [19, 46]. One study using self-assembled peptide hydrogels demonstrated that the incorporation of chondrogenic factors including IGF- 1 and TGF- $\beta 1$ did not significantly improve cartilage regeneration over hydrogels without chondrogenic factors [46]. In a previous in vivo study from our laboratory [19], the single sustained delivery of IGF-1 using OPF composite hydrogels showed significantly improved cartilage regeneration over the single burst delivery of TGF- $\beta 1$ within an osteochondral defect. IGF-1 alone also resulted in a significantly higher score for chondrocyte clustering when compared to the dual delivery of IGF-1 and gel-loaded TGF- $\beta 1$ [19]. Furthermore, several in vivo studies showed a positive result of IGF-1 delivery in cartilage tissue regeneration using other animal models [47-49]. Taken together, the delivery of TGF- $\beta 3$ (at the varying release kinetics examined) with IGF-1 did not improve osteochondral tissue regeneration over the delivery of IGF-1 alone, suggesting a lack of synergy between these two growth factors. Further research investigating the dose-dependent effect of IGF-1 alone on osteochondral tissue regeneration is warranted. 
A comparison between Group 2 and Group 3 reveals no statistical differences in histological scores for subchondral bone evaluation and cartilage regeneration. While in vitro results demonstrate distinct release kinetics between gel-loaded and GMP-loaded TGF- $\beta 3$, in vivo release kinetics may have been different. Indeed, previous studies have shown differences between in vitro and in vivo release kinetics of GFs from composite scaffolds using microparticles as delivery vehicles [50-52]. In one study, the release of BMP-2 from a poly(DL-lactic-co-glycolic acid)/calcium phosphate composite was found to be faster in vivo than from similar composites in vitro $[52,53]$. This highlights the complexity of an in vivo environment and suggests that the release kinetics of TGF- $\beta 3$ in vivo in this study may not have been sufficiently different to elicit a change in osteochondral regeneration. As a result, with the amount of TGF- $\beta 3$ incorporated within the OPF composite hydrogels for Groups 2 and 3, differing release kinetics of TGF- $\beta 3$ together with the presence of IGF-1 did not significantly influence the quality of regenerated osteochondral tissue in a full-thickness defect model.

Compared to a series of previous in vivo studies using OPF composite hydrogels [17-19], PEG with a higher molecular weight $\left(\mathrm{M}_{\mathrm{n}}\right.$ of 35,000$)$ was utilized to synthesize OPF in the present study. As the molecular weight of the PEG chain between crosslinks increases, one would expect that the crosslinking density of the hydrogels would decrease, thus resulting in an increased level of hydrogel degradation $[13,54,55]$. In addition to the faster degradation, it has also been reported that larger network mesh sizes and better transport of nutrients/ signaling molecules as modulated by higher molecular weight of PEG enhanced the chondrogenic differentiation of encapsulated MSCs in OPF composite hydrogels [13]. Furthermore, such modulation in hydrogel properties offers a mode of control over the diffusion of soluble components within hydrogel composites, which is a critical factor for determining the release kinetics of GFs that are incorporated in hydrogels. For instance, when compared to a previous study that used OPF synthesized from PEG with $\mathrm{M}_{n}$ of 25,000 and methylene bisacrylamide as a crosslinker [19], a higher cumulative release of IGF-1 on day 28 (Fig 2) was observed in the present study with the same crosslinking density of GMPs (67.4\% vs $83-85 \%)$.

However, the in vivo degradation of implanted gels using OPF synthesized from PEG with a $M_{n}$ of 35,000 and PEG-DA as a crosslinker in this study was not complete after 12 weeks. One possible factor to affect the degradation is the molar crosslinking ratio of OPF and PEG-DA. When compared to using a lower PEG block $\mathrm{M}_{\mathrm{n}}$ at the same OPF:PEG-DA weight ratio and total polymer content for hydrogel fabrication [17], the current system had a higher molar crosslinking ratio of OPF and PEG-DA which explains the prolonged in vivo degradation. Although the newly formed subchondral bone tissue and neo-cartilage tissue at the site of implant edges were well integrated with the surrounding native tissues, partially degraded gels were often observed in the center of the subchondral region of the defect, regardless of GF loading formulation (Fig 4, 5, 6, and 7). The observation suggests that bone infiltration begins from the defect margin toward the center of the implantation region in the subchondral layer, but bone remodeling in the core area is limited. In addition, the presence of inflammatory cells and fibrous tissue in the subchondral area resulted in low histological scores in bone morphology.

\section{Conclusions}

IGF-1 and TGF- $\beta 3$ were independently released from bilayered OPF composite hydrogels and the release kinetics of TGF- $\beta 3$ could be modulated by the incorporation method. Higher amounts of active TGF- $\beta 3$ were released when it was incorporated with GMPs as compared to gel phase loading. Single delivery of IGF-1 and dual delivery of both IGF-1 and TGF- $\beta 3$ significantly enhanced cartilage morphology over a blank hydrogel control in a full- 
thickness osteochondral defect model after 12 weeks. Although IGF-1 delivery alone contributed to enhanced cartilage repair compared to the dual delivery of IGF-1 and TGF$\beta 3$, there was no significant effect of the TGF- $\beta 3$ release kinetics on osteochondral tissue repair. The lack of synergy between IGF-1 and TGF- $\beta 3$, regardless of TGF- $\beta 3$ kinetics, demonstrates that the dual delivery of GFs does not necessarily confer an improved healing response over the single delivery of GFs in certain tissue engineering applications in vivo.

\section{Acknowledgments}

This work was supported by the National Institutes of Health (R01-AR048756). The authors acknowledge the technical assistance of Dr. Sanne Both and Ms. Natasja van Dijk with the histological analysis of specimens.

\section{References}

1. Temenoff JS, Mikos AG. Review: tissue engineering for regeneration of articular cartilage. Biomaterials. 2000; 21(5):431-440. [PubMed: 10674807]

2. Buckwalter JA, Mow VC, Ratcliffe A. Restoration of Injured or Degenerated Articular Cartilage. J Am Acad Orthop Surg. 1994; 2(4):192-201. [PubMed: 10709009]

3. Goldring MB, Goldring SR. Articular cartilage and subchondral bone in the pathogenesis of osteoarthritis. Ann N Y Acad Sci. 2010; 1192:230-237. [PubMed: 20392241]

4. Ulrich-Vinther M, Maloney MD, Schwarz EM, Rosier R, O'Keefe RJ. Articular cartilage biology. J Am Acad Orthop Surg. 2003; 11(6):421-430. [PubMed: 14686827]

5. Witt KL, Vilensky JA. The anatomy of osteoarthritic joint pain. Clin Anat. 2012 [PubMed: 22730047]

6. Memon AR, Quinlan JF. Surgical treatment of articular cartilage defects in the knee: are we winning? Adv Orthop . 2012; 2012 528423. [PubMed: 22655202]

7. Spiller KL, Maher SA, Lowman AM. Hydrogels for the repair of articular cartilage defects. Tissue Eng Part B Rev. 2011; 17(4):281-299. [PubMed: 21510824]

8. Ge Z, Li C, Heng BC, Cao G, Yang Z. Functional biomaterials for cartilage regeneration. J Biomed Mater Res A. 2012 [PubMed: 22492677]

9. Guo X, Liao J, Park H, Saraf A, Raphael RM, Tabata Y, Kasper FK, Mikos AG. Effects of TGFbeta3 and preculture period of osteogenic cells on the chondrogenic differentiation of rabbit marrow mesenchymal stem cells encapsulated in a bilayered hydrogel composite. Acta Biomater. 2010; 6(8):2920-2931. [PubMed: 20197126]

10. Guo X, Park H, Liu G, Liu W, Cao Y, Tabata Y, Kasper FK, Mikos AG. In vitro generation of an osteochondral construct using injectable hydrogel composites encapsulating rabbit marrow mesenchymal stem cells. Biomaterials. 2009; 30(14):2741-2752. [PubMed: 19232711]

11. Holland TA, Tabata Y, Mikos AG. In vitro release of transforming growth factor-beta 1 from gelatin microparticles encapsulated in biodegradable, injectable oligo(poly(ethylene glycol) fumarate) hydrogels. J Control Release. 2003; 91(3):299-313. [PubMed: 12932709]

12. Holland TA, Tabata Y, Mikos AG. Dual growth factor delivery from degradable oligo(poly(ethylene glycol) fumarate) hydrogel scaffolds for cartilage tissue engineering. J Control Release. 2005; 101(1x02013;3):111-125. [PubMed: 15588898]

13. Park H, Guo X, Temenoff JS, Tabata Y, Caplan AI, Kasper FK, Mikos AG. Effect of swelling ratio of injectable hydrogel composites on chondrogenic differentiation of encapsulated rabbit marrow mesenchymal stem cells in vitro. Biomacromolecules. 2009; 10(3):541-546. [PubMed: 19173557]

14. Park H, Temenoff JS, Holland TA, Tabata Y, Mikos AG. Delivery of TGF-beta1 and chondrocytes via injectable, biodegradable hydrogels for cartilage tissue engineering applications. Biomaterials. 2005; 26(34):7095-7103. [PubMed: 16023196]

15. Park H, Temenoff JS, Tabata Y, Caplan AI, Mikos AG. Injectable biodegradable hydrogel composites for rabbit marrow mesenchymal stem cell and growth factor delivery for cartilage tissue engineering. Biomaterials. 2007; 28(21):3217-3227. [PubMed: 17445882]

16. Park H, Temenoff JS, Tabata Y, Caplan AI, Raphael RM, Jansen JA, Mikos AG. Effect of dual growth factor delivery on chondrogenic differentiation of rabbit marrow mesenchymal stem cells 
encapsulated in injectable hydrogel composites. J Biomed Mater Res A. 2009; 88(4):889-897. [PubMed: 18381637]

17. Guo X, Park H, Young S, Kretlow JD, van den Beucken JJ, Baggett LS, Tabata Y, Kasper FK, Mikos AG, Jansen JA. Repair of osteochondral defects with biodegradable hydrogel composites encapsulating marrow mesenchymal stem cells in a rabbit model. Acta Biomater. 2010; 6(1):3947. [PubMed: 19660580]

18. Holland TA, Bodde EW, Baggett LS, Tabata Y, Mikos AG, Jansen JA. Osteochondral repair in the rabbit model utilizing bilayered, degradable oligo(poly(ethylene glycol) fumarate) hydrogel scaffolds. J Biomed Mater Res A. 2005; 75(1):156-167. [PubMed: 16052490]

19. Holland TA, Bodde EW, Cuijpers VM, Baggett LS, Tabata Y, Mikos AG, Jansen JA. Degradable hydrogel scaffolds for in vivo delivery of single and dual growth factors in cartilage repair. Osteoarthritis Cartilage. 2007; 15(2):187-197. [PubMed: 16965923]

20. Barry F, Boynton RE, Liu B, Murphy JM. Chondrogenic differentiation of mesenchymal stem cells from bone marrow: differentiation-dependent gene expression of matrix components. Exp Cell Res. 2001; 268(2):189-200. [PubMed: 11478845]

21. Kurth T, Hedbom E, Shintani N, Sugimoto M, Chen FH, Haspl M, Martinovic S, Hunziker EB. Chondrogenic potential of human synovial mesenchymal stem cells in alginate. Osteoarthritis Cartilage. 2007; 15(10):1178-1189. [PubMed: 17502159]

22. Park JS, Yang HJ, Woo DG, Yang HN, Na K, Park KH. Chondrogenic differentiation of mesenchymal stem cells embedded in a scaffold by long-term release of TGF-beta 3 complexed with chondroitin sulfate. J Biomed Mater Res A. 2010; 92(2):806-816. [PubMed: 19280636]

23. Sampat SR, O'Connell GD, Fong JV, Alegre-Aguaron E, Ateshian GA, Hung CT. Growth factor priming of synovium-derived stem cells for cartilage tissue engineering. Tissue Eng Part A. 2011; 17(17-18):2259-2265. [PubMed: 21542714]

24. Bian L, Zhai DY, Tous E, Rai R, Mauck RL, Burdick JA. Enhanced MSC chondrogenesis following delivery of TGF-beta3 from alginate microspheres within hyaluronic acid hydrogels in vitro and in vivo. Biomaterials. 2011; 32(27):6425-6434. [PubMed: 21652067]

25. Fan H, Tao H, Wu Y, Hu Y, Yan Y, Luo Z. TGF-beta3 immobilized PLGAgelatin/ chondroitin sulfate/hyaluronic acid hybrid scaffold for cartilage regeneration. J Biomed Mater Res A. 2010; 95(4):982-992. [PubMed: 20872747]

26. Lee CH, Cook JL, Mendelson A, Moioli EK, Yao H, Mao JJ. Regeneration of the articular surface of the rabbit synovial joint by cell homing: a proof of concept study. Lancet. 2010; 376(9739): 440-448. [PubMed: 20692530]

27. Park JS, Yang HN, Woo DG, Chung HM, Park KH. In vitro and in vivo chondrogenesis of rabbit bone marrow-derived stromal cells in fibrin matrix mixed with growth factor loaded in nanoparticles. Tissue Eng Part A. 2009; 15(8):2163-2175. [PubMed: 19413492]

28. Fukumoto T, Sperling JW, Sanyal A, Fitzsimmons JS, Reinholz GG, Conover CA, O'Driscoll SW. Combined effects of insulin-like growth factor-1 and transforming growth factorbeta 1 on periosteal mesenchymal cells during chondrogenesis in vitro. Osteoarthritis Cartilage. 2003; 11(1): 55-64. [PubMed: 12505488]

29. Fortier LA, Barker JU, Strauss EJ, McCarrel TM, Cole BJ. The role of growth factors in cartilage repair. Clin Orthop Relat Res. 2011; 469(10):2706-2715. [PubMed: 21403984]

30. Chopra R, Anastassiades T. Specificity and synergism of polypeptide growth factors in stimulating the synthesis of proteoglycans and a novel high molecular weight anionic glycoprotein by articular chondrocyte cultures. J Rheumatol. 1998; 25(8):1578-1584. [PubMed: 9712104]

31. Yaeger PC, Masi TL, de Ortiz JL, Binette F, Tubo R, McPherson JM. Synergistic action of transforming growth factor-beta and insulin-like growth factor-I induces expression of type II collagen and aggrecan genes in adult human articular chondrocytes. Exp Cell Res. 1997; 237(2): 318-325. [PubMed: 9434627]

32. Worster AA, Brower-Toland BD, Fortier LA, Bent SJ, Williams J, Nixon AJ. Chondrocytic differentiation of mesenchymal stem cells sequentially exposed to transforming growth factorbeta1 in monolayer and insulin-like growth factor-I in a three-dimensional matrix. J Orthop Res. 2001; 19(4):738-749. [PubMed: 11518286] 
33. Goepfert C, Slobodianski A, Schilling AF, Adamietz P, Portner R. Cartilage engineering from mesenchymal stem cells. Adv Biochem Eng Biotechnol. 2010; 123:163-200. [PubMed: 20535603]

34. Santo VE, Gomes ME, Mano JF, Reis RL. Controlled Release Strategies for Bone, Cartilage, and Osteochondral Engineering-Part II: Challenges on the Evolution from Single to Multiple Bioactive Factor Delivery. Tissue Eng Part B Rev. 2013

35. Vinatier C, Mrugala D, Jorgensen C, Guicheux J, Noel D. Cartilage engineering: a crucial combination of cells, biomaterials and biofactors. Trends Biotechnol. 2009; 27(5):307-314 [PubMed: 19329205]

36. Ng KW, O'Conor CJ, Kugler LE, Cook JL, Ateshian GA, Hung CT. Transient supplementation of anabolic growth factors rapidly stimulates matrix synthesis in engineered cartilage. Ann Biomed Eng. 2011; 39(10):2491-2500. [PubMed: 21833681]

37. Kim M, Erickson IE, Choudhury M, Pleshko N, Mauck RL. Transient exposure to TGF-beta3 improves the functional chondrogenesis of MSC-laden hyaluronic acid hydrogels. J Mech Behav Biomed Mater. 2012; 11:92-101. [PubMed: 22658158]

38. Wang L, Detamore MS. Insulin-like growth factor-I improves chondrogenesis of predifferentiated human umbilical cord mesenchymal stromal cells. J Orthop Res. 2009; 27(8):1109-1115. [PubMed: 19195026]

39. Kinard LA, Kasper FK, Mikos AG. Synthesis of oligo(poly(ethylene glycol) fumarate). Nat Protoc. 2012; 7(6):1219-1227. [PubMed: 22653160]

40. Jo S, Shin H, Shung AK, Fisher JP, Mikos AG. Synthesis and characterization of oligo(poly(ethylene glycol) fumarate) macromer. Macromolecules. 2001; 34(9):2839-2844.

41. Parker JA, Brunner G, Walboomers XF, Von den Hoff JW, Maltha JC, Jansen JA. Release of bioactive transforming growth factor beta(3) from microtextured polymer surfaces in vitro and in vivo. Tissue Eng. 2002; 8(5):853-861. [PubMed: 12459064]

42. Jaklenec A, Hinckfuss A, Bilgen B, Ciombor DM, Aaron R, Mathiowitz E. Sequential release of bioactive IGF-I and TGF-beta 1 from PLGA microsphere-based scaffolds. Biomaterials. 2008; 29(10):1518-1525. [PubMed: 18166223]

43. Tabata Y, Hijikata S, Muniruzzaman M, Ikada Y. Neovascularization effect of biodegradable gelatin microspheres incorporating basic fibroblast growth factor. J Biomater Sci Polym Ed. 1999; 10(1):79-94. [PubMed: 10091924]

44. Lian JB, Stein GS. Concepts of osteoblast growth and differentiation: basis for modulation of bone cell development and tissue formation. Crit Rev Oral Biol Med. 1992; 3(3):269-305. [PubMed: 1571474]

45. Moioli EK, Hong L, Mao JJ. Inhibition of osteogenic differentiation of human mesenchymal stem cells. Wound Repair Regen. 2007; 15(3):413-421. [PubMed: 17537129]

46. Miller RE, Grodzinsky AJ, Vanderploeg EJ, Lee C, Ferris DJ, Barrett MF, Kisiday JD, Frisbie DD. Effect of self-assembling peptide, chondrogenic factors, and bone marrow-derived stromal cells on osteochondral repair. Osteoarthritis Cartilage. 2010; 18(12):1608-1619. [PubMed: 20851201]

47. Fortier LA, Mohammed HO, Lust G, Nixon AJ. Insulin-like growth factor-I enhances cell-based repair of articular cartilage. J Bone Joint Surg Br. 2002; 84(2):276-288. [PubMed: 11922373]

48. Schmidt MB, Chen EH, Lynch SE. A review of the effects of insulin-like growth factor and platelet derived growth factor on in vivo cartilage healing and repair. Osteoarthritis Cartilage. 2006; 14(5):403-412. [PubMed: 16413799]

49. Nixon AJ, Fortier LA, Williams J, Mohammed H. Enhanced repair of extensive articular defects by insulin-like growth factor-I-laden fibrin composites. J Orthop Res. 1999; 17(4):475-487. [PubMed: 10459752]

50. Patel ZS, Ueda H, Yamamoto M, Tabata Y, Mikos AG. In vitro and in vivo release of vascular endothelial growth factor from gelatin microparticles and biodegradable composite scaffolds. Pharm Res. 2008; 25(10):2370-2378. [PubMed: 18663411]

51. Patel ZS, Yamamoto M, Ueda H, Tabata Y, Mikos AG. Biodegradable gelatin microparticles as delivery systems for the controlled release of bone morphogenetic protein-2. Acta Biomater. 2008; 4(5):1126-1138. [PubMed: 18474452] 
52. Ruhe PQ, Boerman OC, Russel FG, Spauwen PH, Mikos AG, Jansen JA. Controlled release of rhBMP-2 loaded poly(dl-lactic-co-glycolic acid)/calcium phosphate cement composites in vivo. J Control Release. 2005; 106(1-2):162-171. [PubMed: 15972241]

53. Ruhe PQ, Hedberg EL, Padron NT, Spauwen PH, Jansen JA, Mikos AG. rhBMP-2 release from injectable poly(DL-lactic-co-glycolic acid)/calcium-phosphate cement composites. J Bone Joint Surg Am. 2003; 85-A Suppl 3:75-81. [PubMed: 12925613]

54. Shin H, Jo S, Mikos AG. Modulation of marrow stromal osteoblast adhesion on biomimetic oligo[poly(ethylene glycol) fumarate] hydrogels modified with Arg-Gly-Asp peptides and a poly(ethyleneglycol) spacer. J Biomed Mater Res. 2002; 61(2):169-179. [PubMed: 12061329]

55. Shin H, Zygourakis K, Farach-Carson MC, Yaszemski MJ, Mikos AG. Modulation of differentiation and mineralization of marrow stromal cells cultured on biomimetic hydrogels modified with Arg-Gly-Asp containing peptides. J Biomed Mater Res A. 2004; 69(3):535-543. [PubMed: 15127400] 
(A)

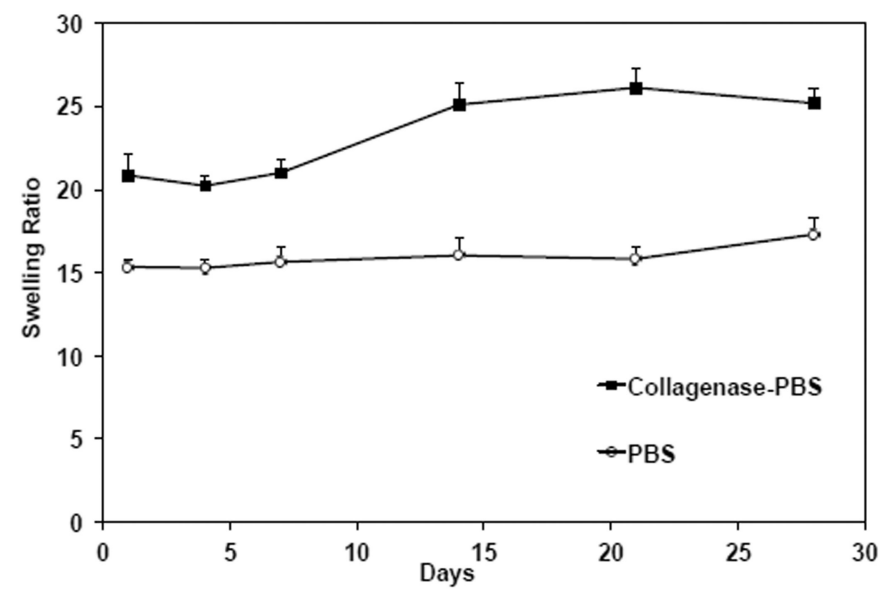

(C)

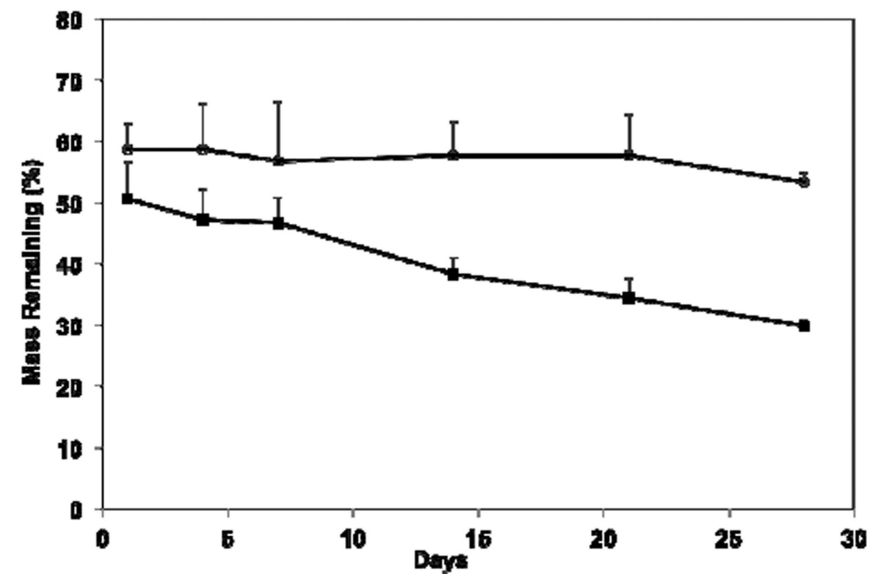

(B)

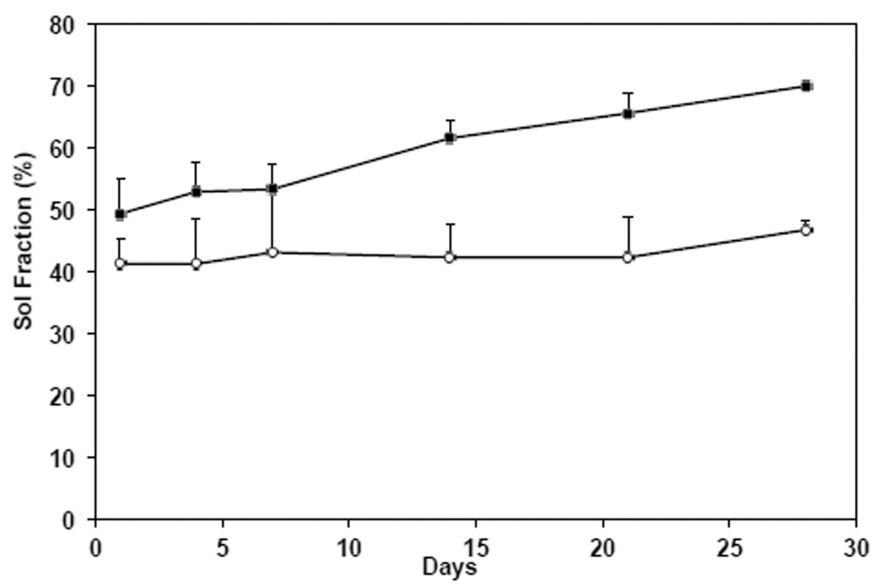

Fig. 1.

Degradation profile of bilayered OPF composite hydrogels. Swelling ratio (A), sol fraction (B), and mass remaining (C) were measured over 28 days in collagenase containing PBS (ש) and PBS $(\circ)(\mathrm{n}=4)$. Error bars correspond to standard deviation. 
(A)

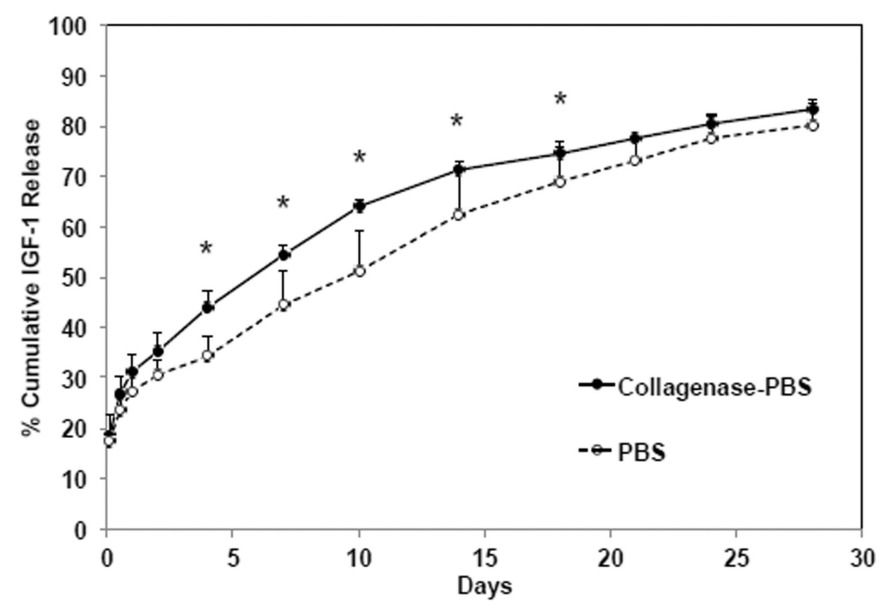

(C)

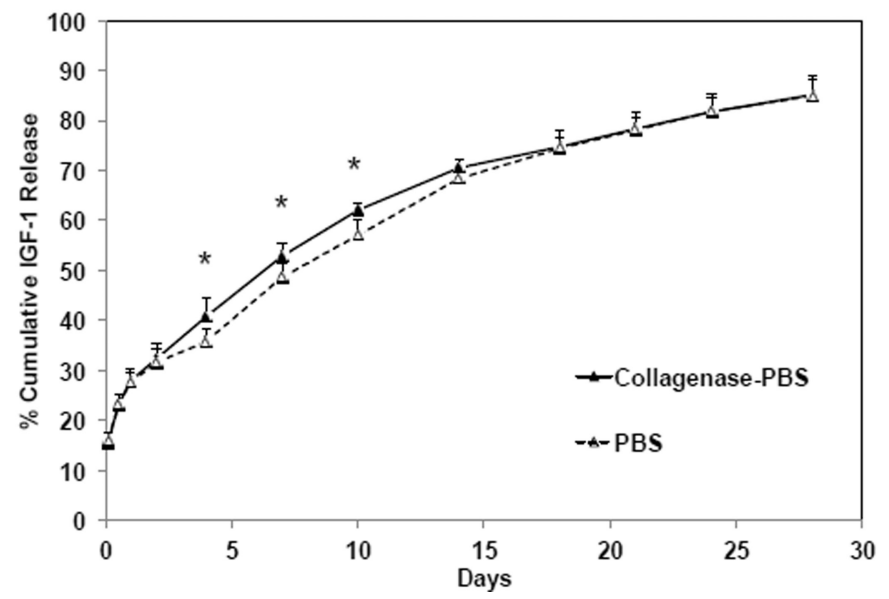

(B)

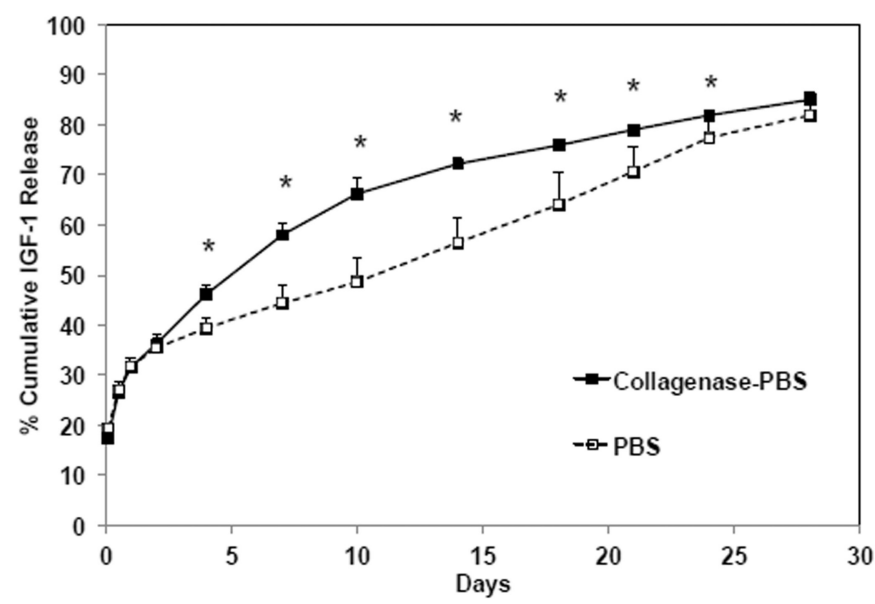

(D)

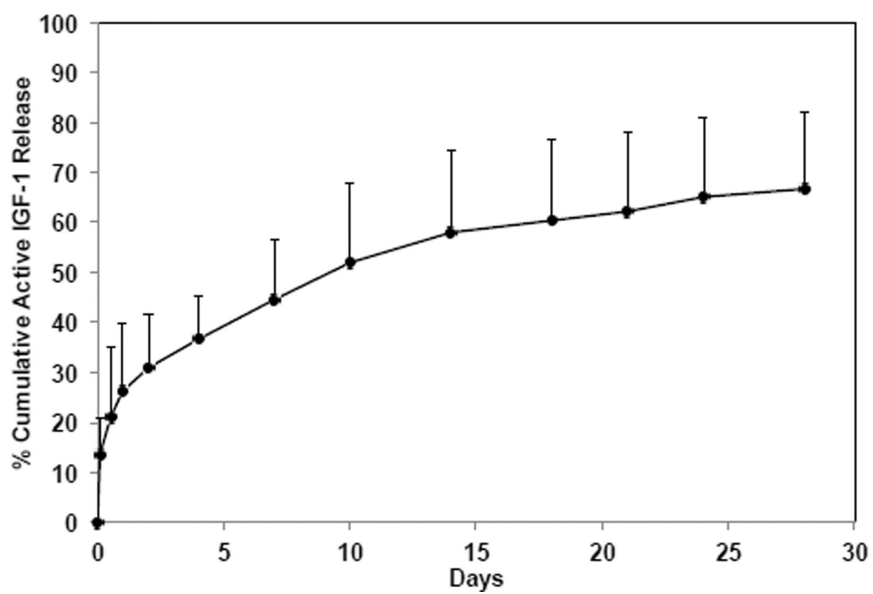

Fig. 2.

$\%$ cumulative IGF-1 release from a bilayered OPF composite hydrogels in Group 1 (A), Group 2 (B), and Group 3 (C) over 28 days $(n=5)$. Solid line indicates collagenase-PBS condition while dashed line indicates PBS condition. \% cumulative active IGF-1 release from a hydrogel in Group 1 (IGF-1 only) in collagenase-PBS is shown in (D) $(n=4)$. Error bars correspond to standard deviation. $(*)$ indicates a significant difference between groups $(\mathrm{p}<0.05)$. 
(A)

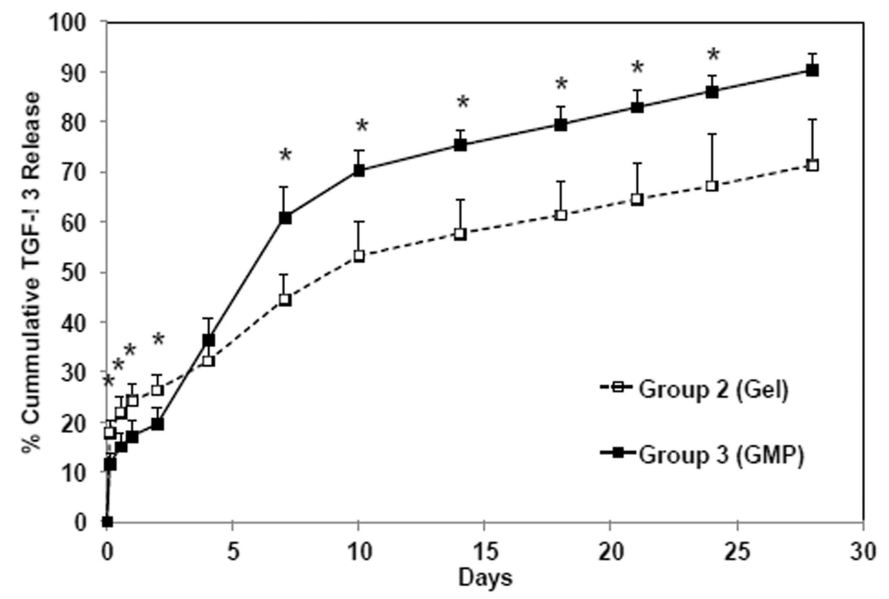

(C)

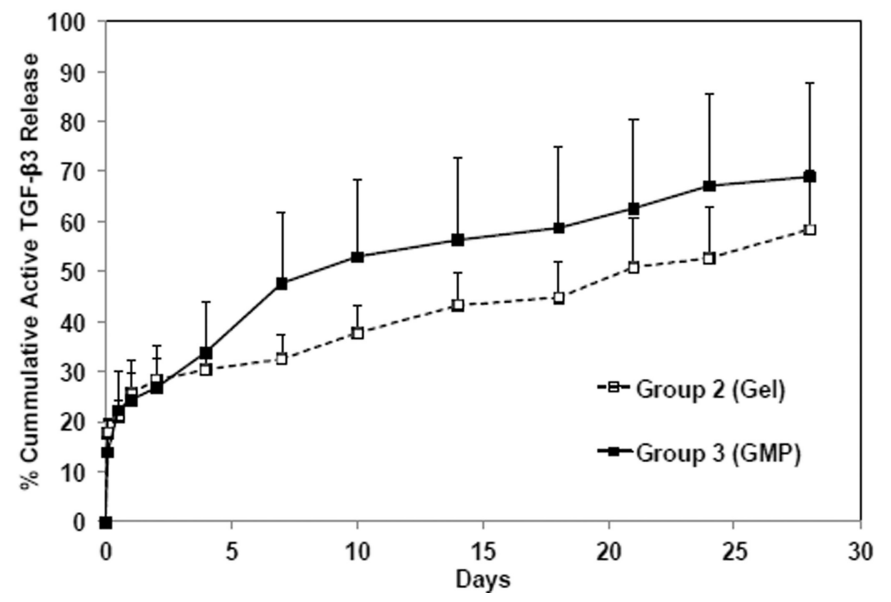

(B)

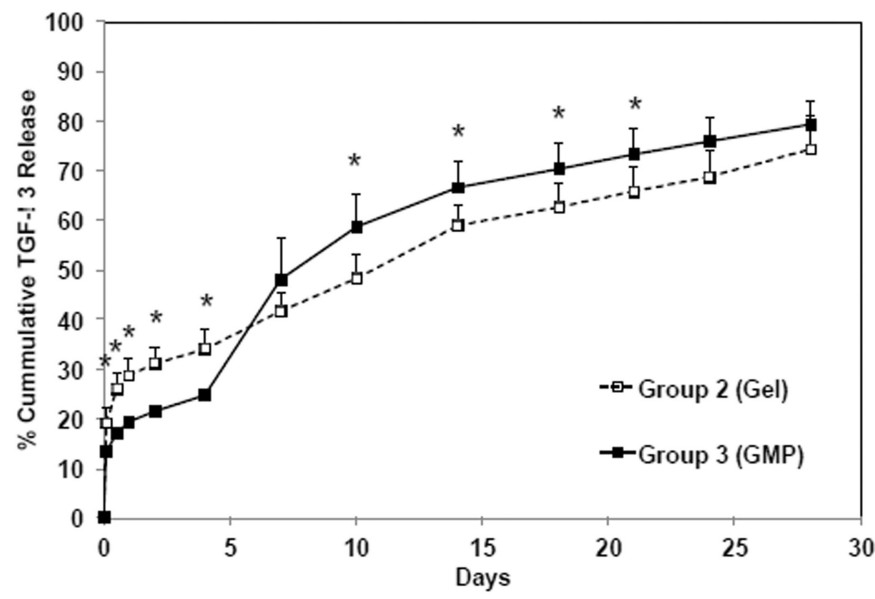

Fig. 3.

$\%$ cumulative TGF- $\beta 3$ release from a bilayered OPF composite hydrogels in Group 2 (solid line) and Group 3 (dashed line) in collagenase-PBS (A) and PBS (B) over 28 days $(n=5) . \%$ cumulative active TGF- $\beta 3$ release from a hydrogel in Group 2 (solid line) and Group 3 (dashed line) in collagenase-PBS is shown in $(C)(n=4)$. Error bars correspond to standard deviation. $(*)$ indicates a significant difference between groups $(\mathrm{p}<0.05)$. 
(A)

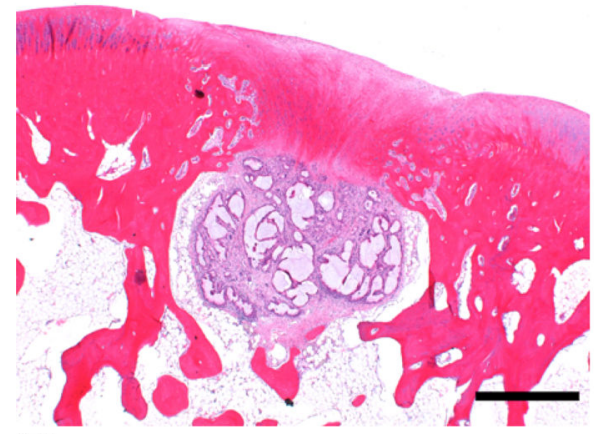

(D)

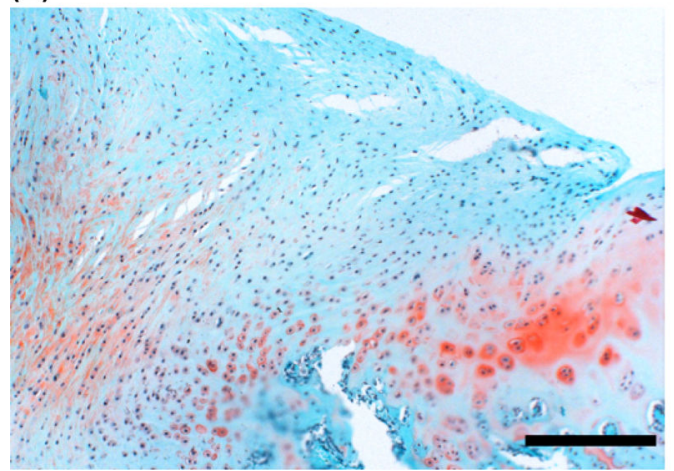

(B)

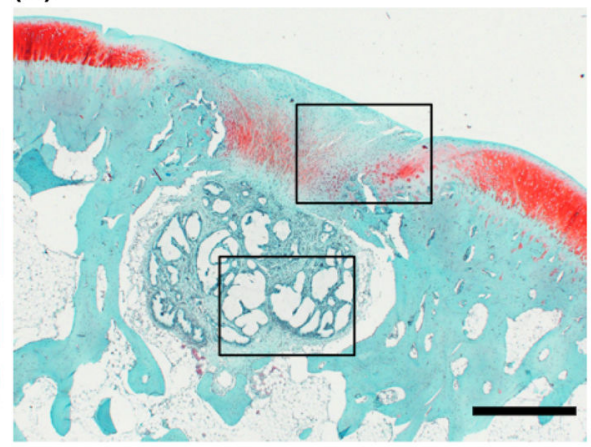

(E)

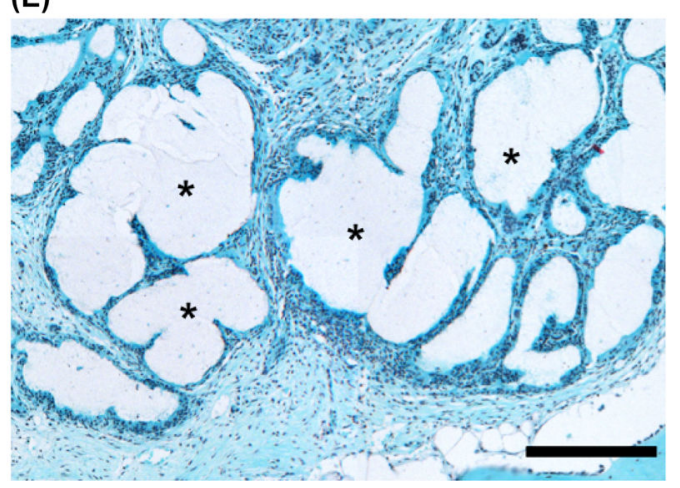

(C)

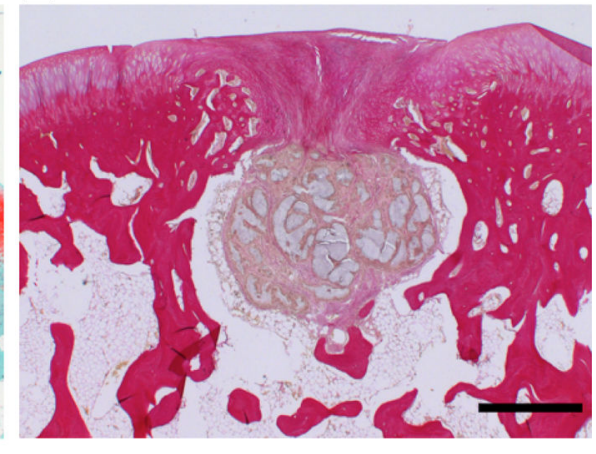

Fig. 4.

Representative histological sections of osteochondral tissue formation after 12 weeks of implantation of OPF composite hydrogels in control (blank without GFs). Sections were stained with H\&E (A), Safranin-O/Fast Green (B), and van Gieson's Picrofuchsin (C) (Scale bar: $1000 \mu \mathrm{m})$. Images indicate a thick fibrous layer with a discontinuity in morphology compared to adjacent host cartilage tissue and incomplete degradation of hydrogels in the subchondral area along with inflammatory cell infiltration. Boxed regions are shown with a higher magnification (D, E) (Scale bar: $250 \mu \mathrm{m})$. (*) indicates some partially degraded OPF composite hydrogels remaining in the defect site. 
(A)

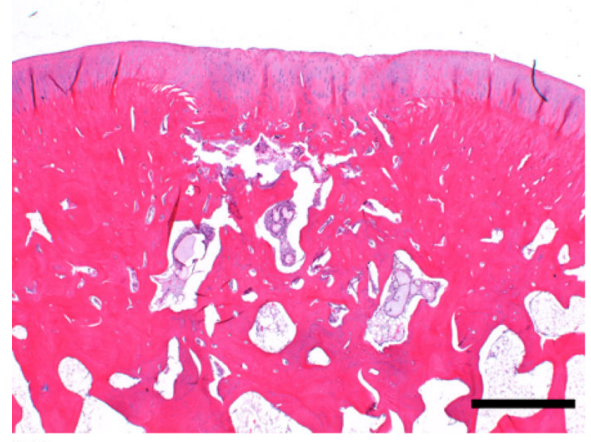

(D)

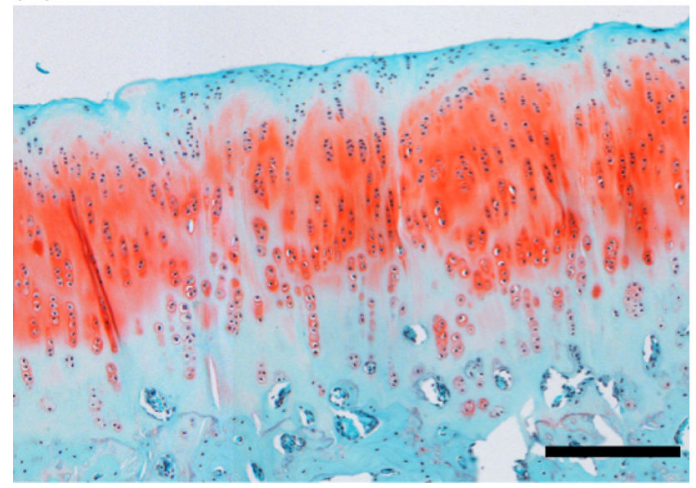

(B)

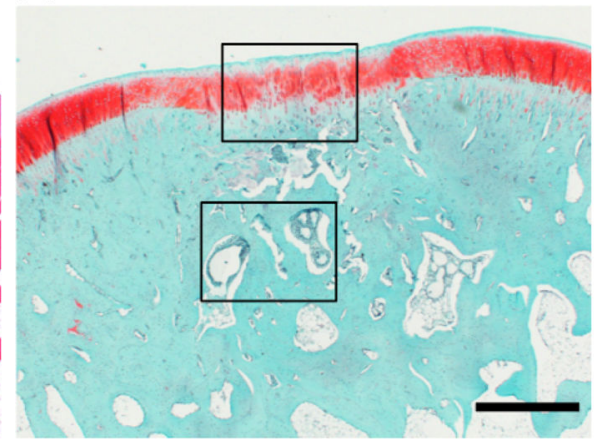

(C)

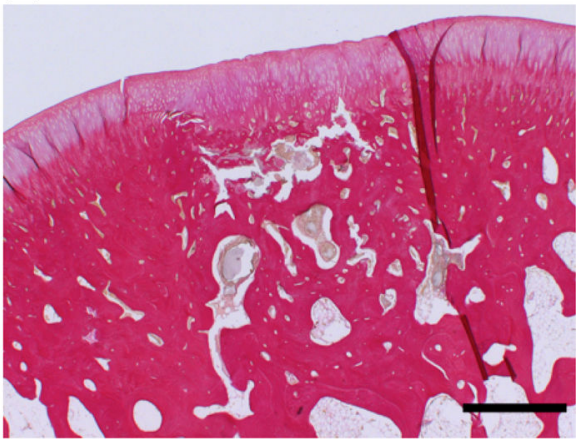

(E)

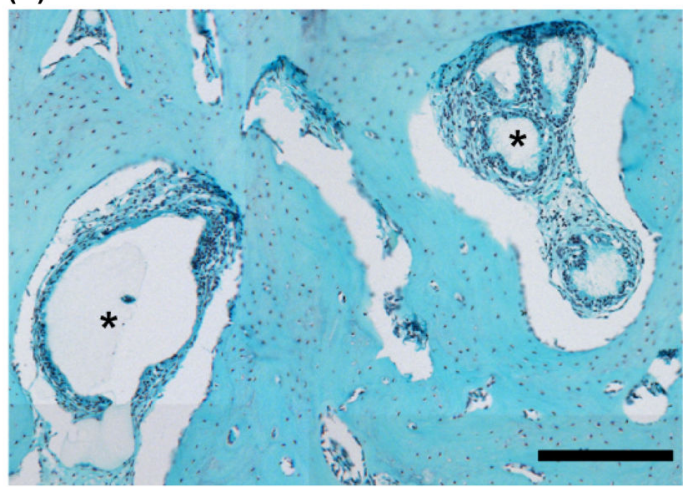

Fig. 5.

Representative histological sections of osteochondral tissue formation after 12 weeks of implantation of OPF composite hydrogels in Group 1 (IGF-1 only). Sections were stained with H\&E (A), Safranin-O/Fast Green (B), and van Gieson's Picrofuchsin (C) (Scale bar: $1000 \mu \mathrm{m}$ ). Images with higher magnification indicate hyaline-like cartilage morphology with a hierarchical aligning of chondrocytes in the cartilage region (D) and a small fraction of partially degraded OPF composite hydrogels (indicated by *) in the subchondral area (E) (Scale bar: $250 \mu \mathrm{m}$ ) 
(A)

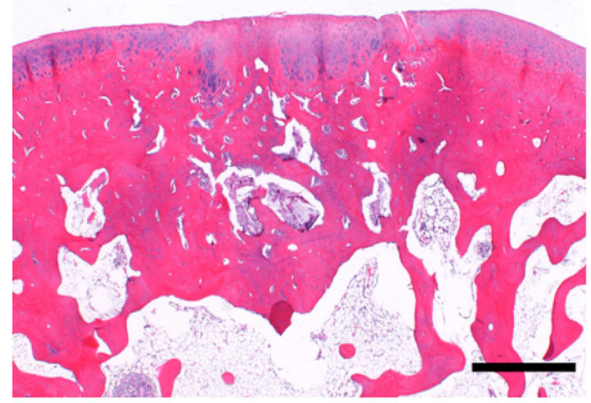

(D)

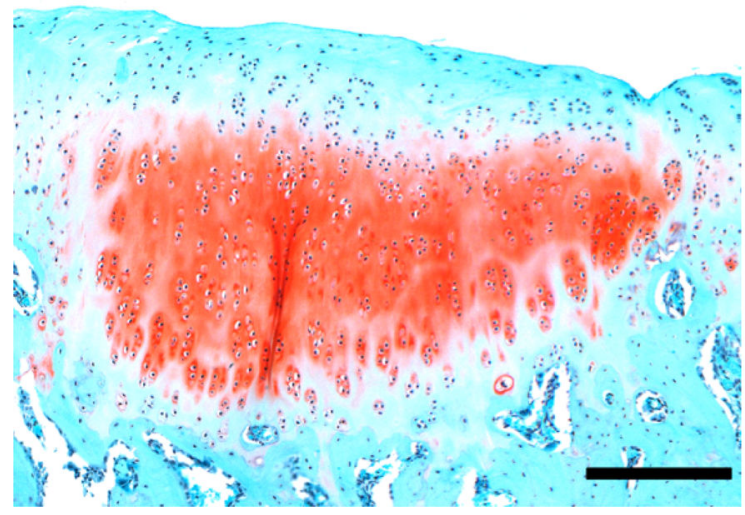

(C)
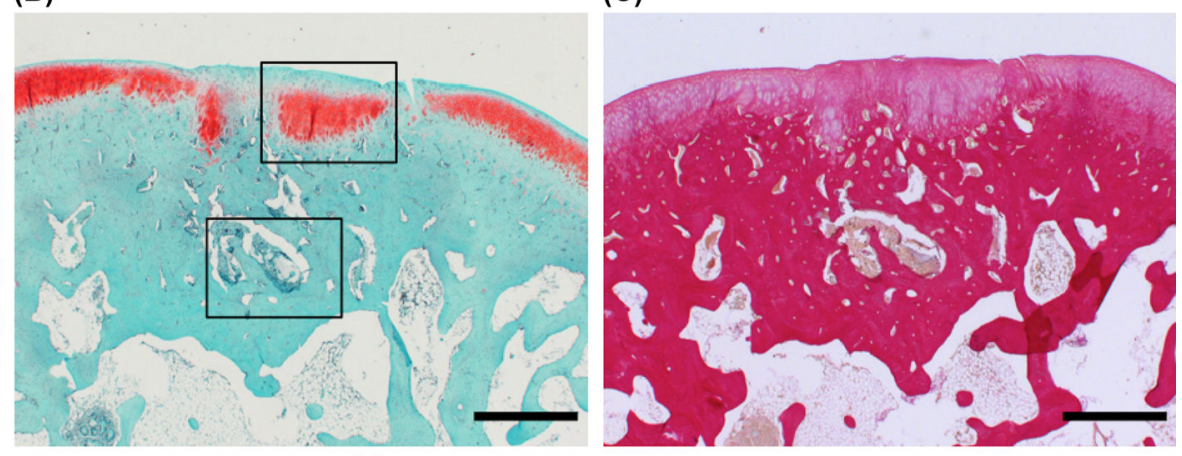

(E)

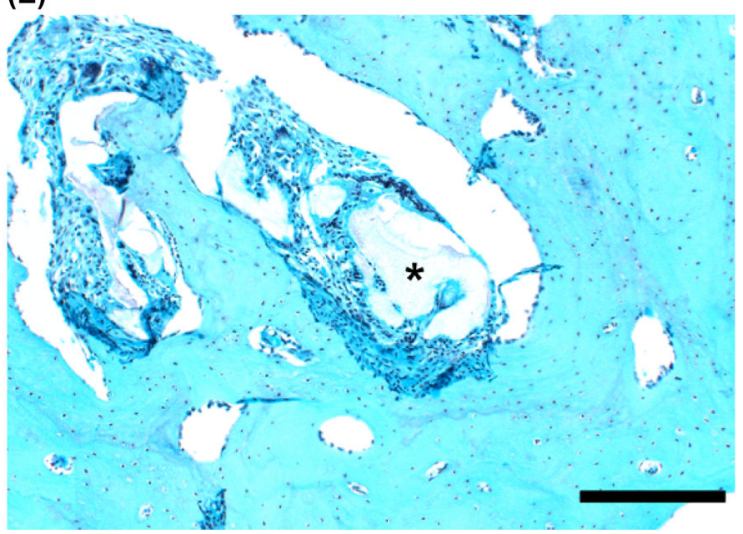

Fig. 6.

Representative histological sections of osteochondral tissue formation after 12 weeks of implantation of OPF composite hydrogels in Group 2 (IGF-1 and gel-loaded TGF- $\beta 3$ ).

Sections were stained with H\&E (A), Safranin-O/Fast Green (B), and van Gieson's Picrofuchsin (C) (Scale bar: $1000 \mu \mathrm{m}$ ). Images with higher magnification indicate hyalinelike cartilage morphology with GAG staining in the cartilage region (D) and partially degraded OPF composite hydrogels (indicated by *) that are surrounded by regenerated bone tissue in the subchondral area (E) (Scale bar: $250 \mu \mathrm{m}$ ) 
(A)

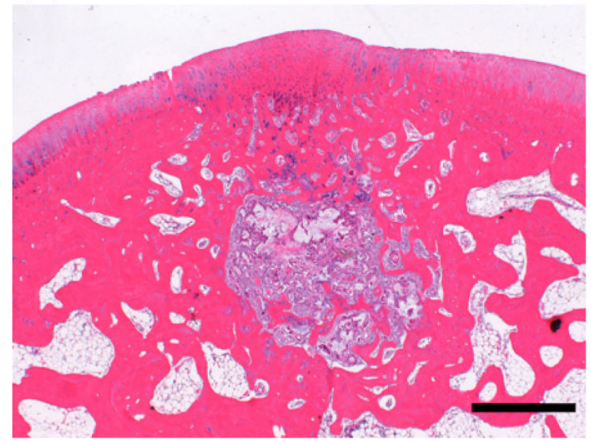

(D)

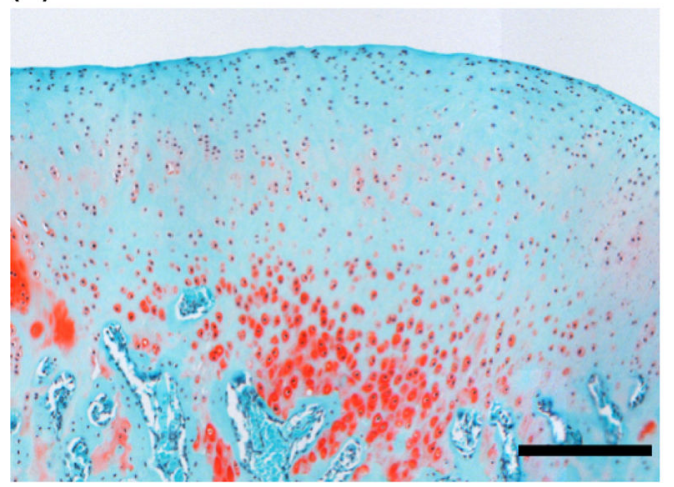

(B)

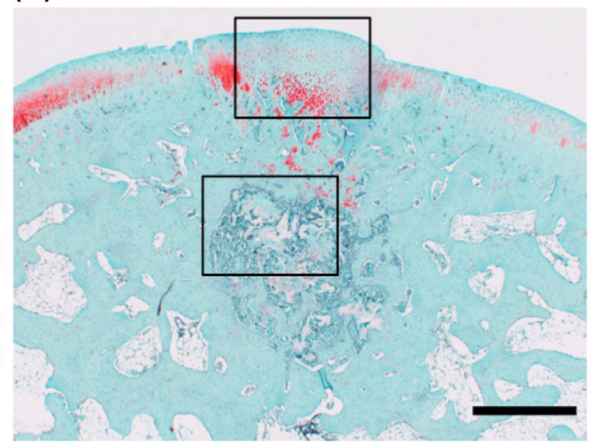

(C)

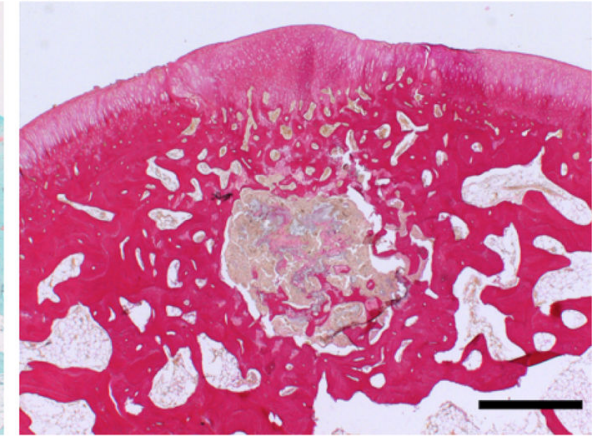

(E)

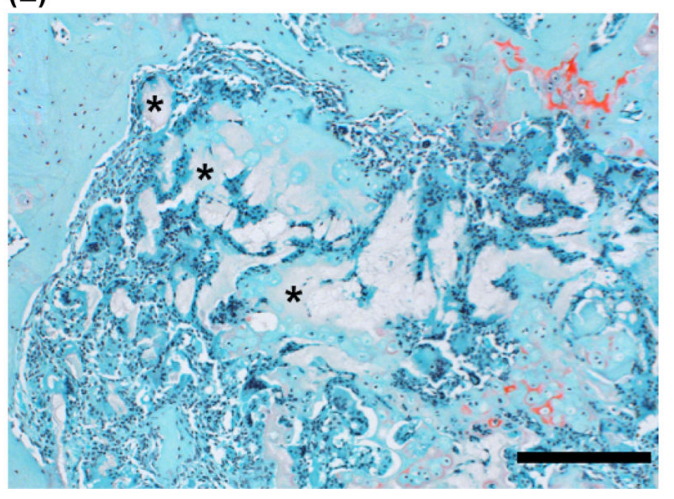

Fig. 7.

Representative histological sections of osteochondral tissue formation after 12 weeks of implantation of OPF composite hydrogels in Group 3 (IGF-1 and GMP-loaded TGF- $\beta 3$ ).

Sections were stained with H\&E (A), Safranin-O/Fast Green (B), and van Gieson's

Picrofuchsin (C) (Scale bar: $1000 \mu \mathrm{m})$. Images with higher magnification indicate fibrocartilage formation in the cartilage region (D) and a similar subchondral bone morphology with large volume of partially degraded OPF composite hydrogels (indicated by *) compared to the control specimen (E) (Scale bar: $250 \mu \mathrm{m}$ ) 
(A)

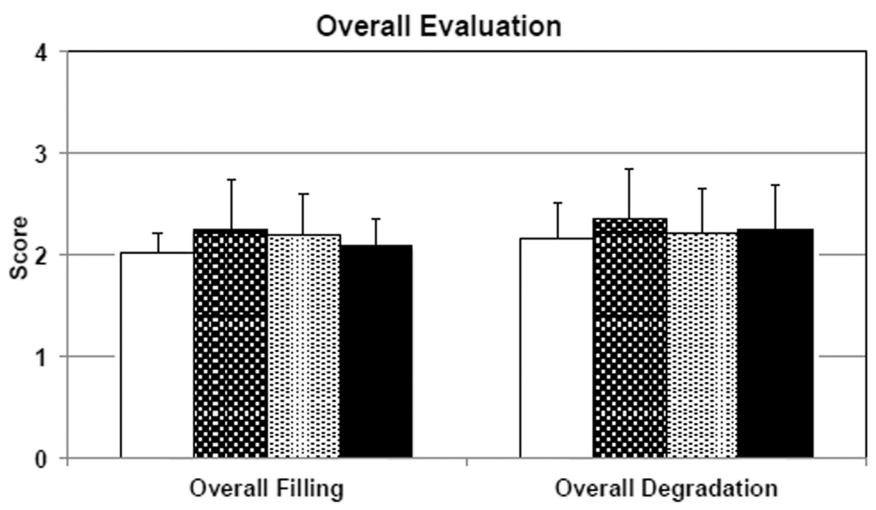

(B)

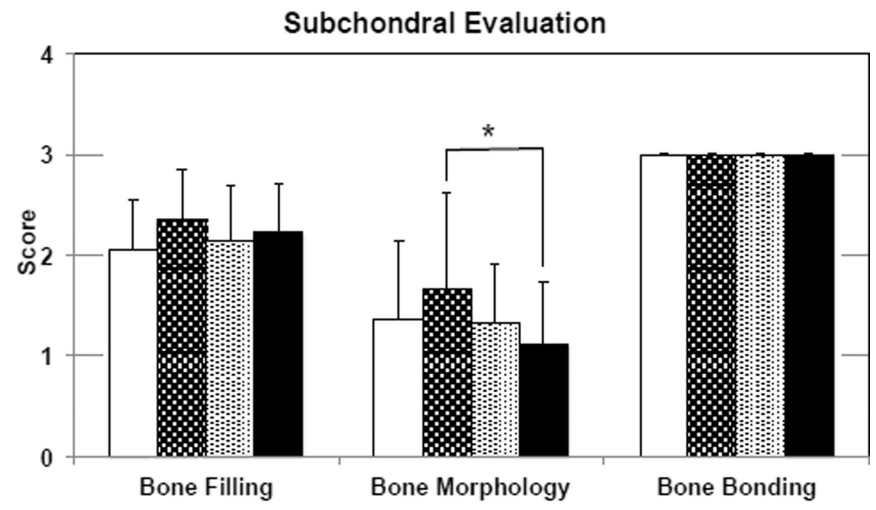

(C)

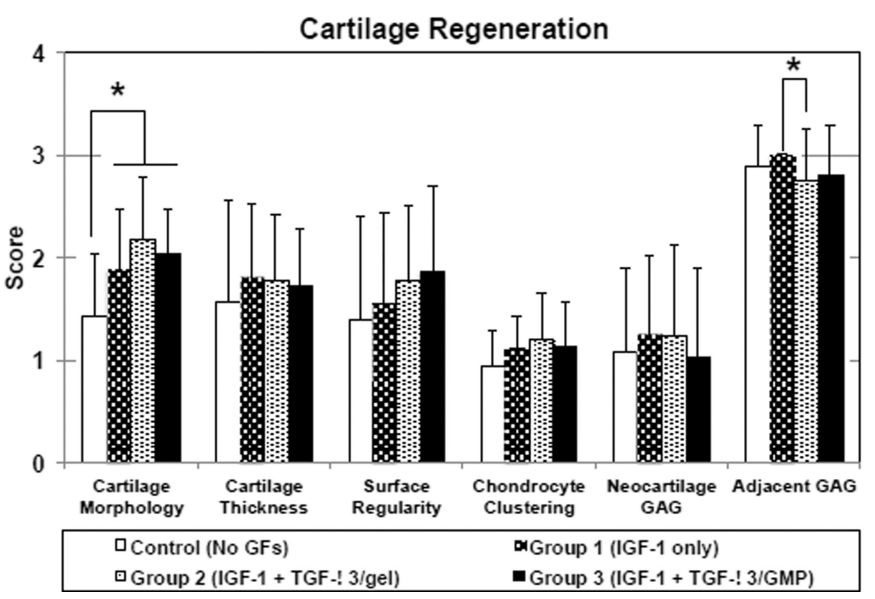

Fig. 8.

Histological scoring for overall defect (A), subchondral region (B), and cartilage region (C). Overall evaluation (A) includes overall tissue filling and overall implant degradation; subchondral evaluation (B) includes bone filling, bone morphology, and bonding to adjacent tissue; cartilage evaluation (C) includes cartilage morphology, cartilage thickness, surface regularity, chondrocyte clustering, chondrocyte and GAG amount in neocartilage, and chondrocyte and GAG amount in adjacent cartilage. Data are shown as average scores with error bars representing standard deviation. $\left(^{*}\right)$ indicates a significant difference between groups $(\mathrm{p}<0.05)$. 
(A)

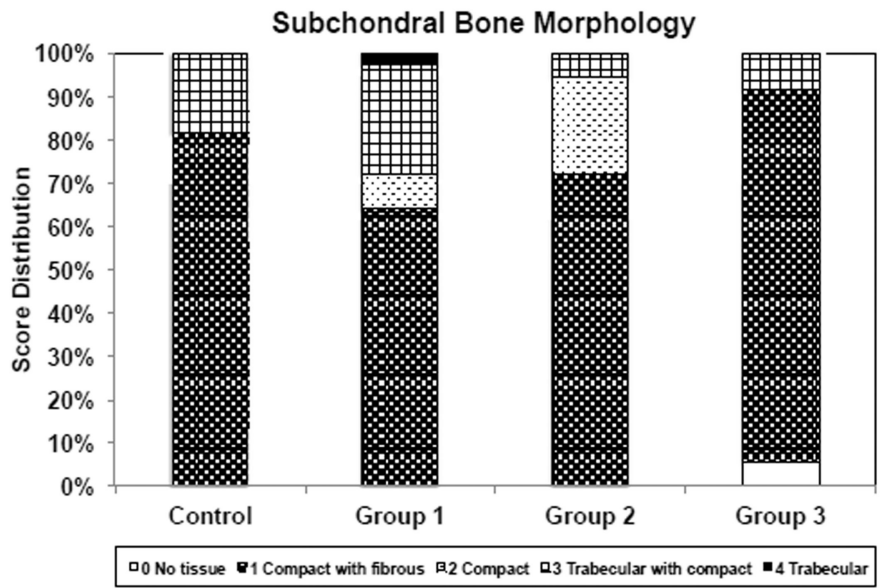

(B)

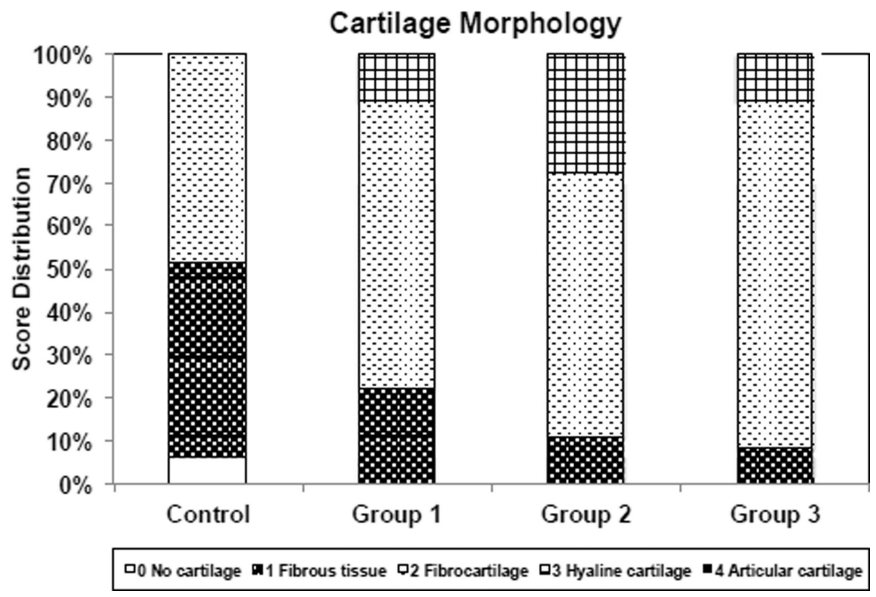

Fig. 9.

Histological score distribution for subchondral bone morphology (A) and cartilage morphology (B) for the four groups tested. 


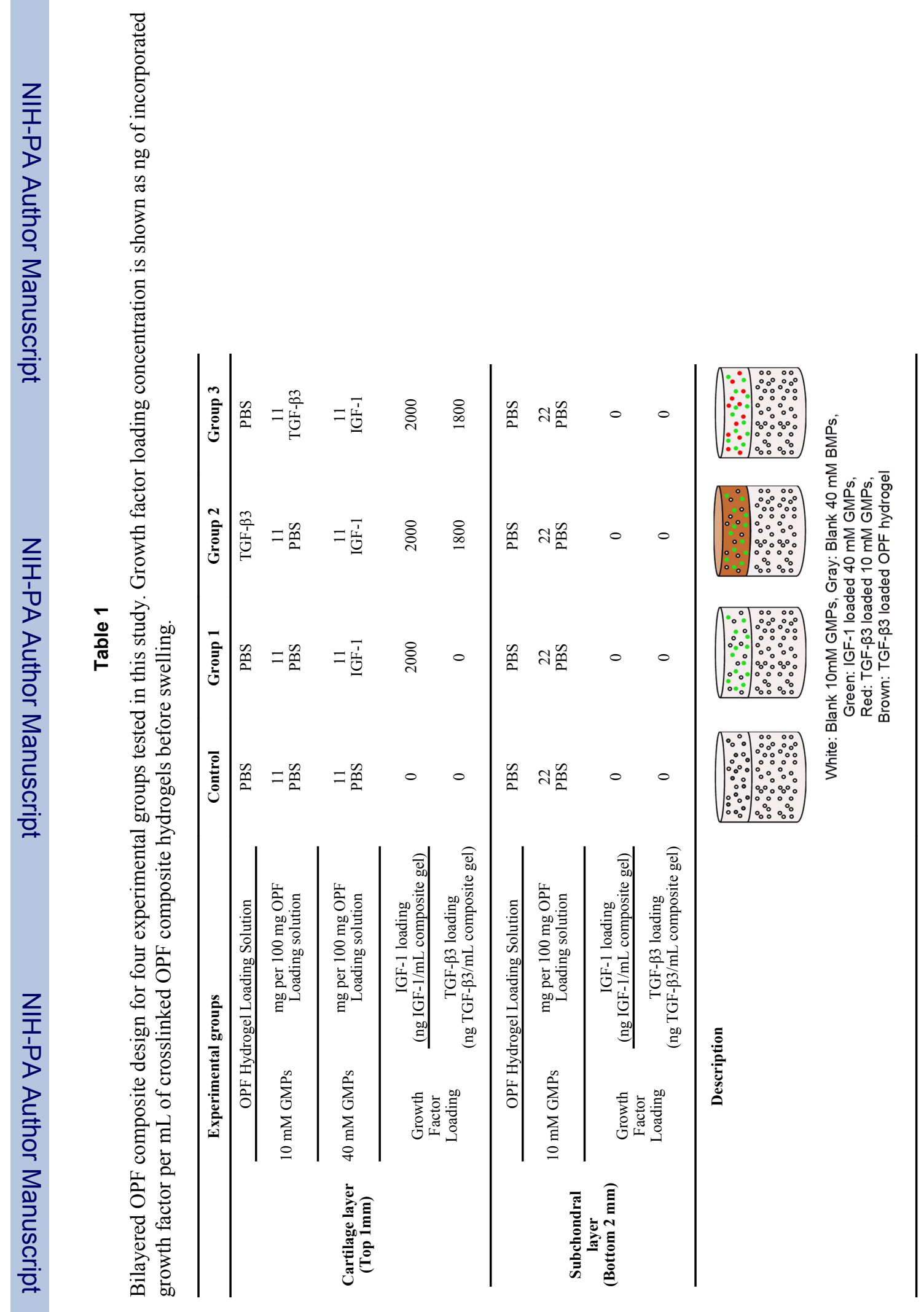


Table 2

Histological scoring system for (A) overall tissue evaluation, (B) subchondral bone evaluation, and (C) cartilage evaluation in rabbit osteochondral defects [17].

\begin{tabular}{|c|c|}
\hline & Score \\
\hline \multicolumn{2}{|l|}{ (a) Overall defect evaluation (throughout the entire defect depth) } \\
\hline \multicolumn{2}{|l|}{ 1. Percent filling with newly formed tissue } \\
\hline $100 \%$ & 3 \\
\hline$>50 \%$ & 2 \\
\hline$<50 \%$ & 1 \\
\hline $0 \%$ & 0 \\
\hline \multicolumn{2}{|l|}{ 2. Percent degradation of the implant } \\
\hline $100 \%$ & 3 \\
\hline$>50 \%$ & 2 \\
\hline$<50 \%$ & 1 \\
\hline $0 \%$ & 0 \\
\hline \multicolumn{2}{|l|}{ (b) Subchondral bone evaluation (within the bottom $2 \mathrm{~mm}$ of defect) } \\
\hline \multicolumn{2}{|l|}{ 3. Percent filling with newly formed tissue } \\
\hline $100 \%$ & 3 \\
\hline$>50 \%$ & 2 \\
\hline$<50 \%$ & 1 \\
\hline $0 \%$ & 0 \\
\hline \multicolumn{2}{|l|}{ 4. Subchondral bone morphology } \\
\hline Normal, trabecular bone & 4 \\
\hline Trabecular bone, with some compact bone & 3 \\
\hline Compact bone & 2 \\
\hline Compact bone and fibrous tissue & 1 \\
\hline Only fibrous tissue or no tissue & 0 \\
\hline \multicolumn{2}{|l|}{ 5. Extent of new tissue bonding with adjacent bone } \\
\hline Complete on both edges & 3 \\
\hline Complete on one edge & 2 \\
\hline Partial on both edges & 1 \\
\hline Without continuity on either edge & 0 \\
\hline \multicolumn{2}{|l|}{ (C) Cartilage evaluation (within the upper $1 \mathrm{~mm}$ of defect) } \\
\hline \multicolumn{2}{|l|}{ 6. Morphology of newly formed surface tissue } \\
\hline Exclusively articular cartilage & 4 \\
\hline Mainly hyaline cartilage & 3 \\
\hline Fibrocartilage (spherical morphology observed with $\geq 75 \%$ of cells) & 2 \\
\hline Only fibrous cartilage (spherical morphology observed with $<75 \%$ of cells) & 1 \\
\hline No tissue & 0 \\
\hline \multicolumn{2}{|l|}{ 7.Thickness of newly formed cartilage } \\
\hline Similar to the surrounding cartilage & 3 \\
\hline Greater than the surrounding cartilage & 2 \\
\hline
\end{tabular}




\begin{tabular}{lc}
\hline & Score \\
\hline Less than the surrounding cartilage & 1 \\
No cartilage & 0 \\
8. Joint surface regularity & \\
Smooth, intact surface & 3 \\
Surface fissures (<25\% of new surface thickness) & 2 \\
Deep fissures ( $\geq 25 \%$ of new surface thickness) & 1 \\
Complete disruption of the new surface & 0
\end{tabular}




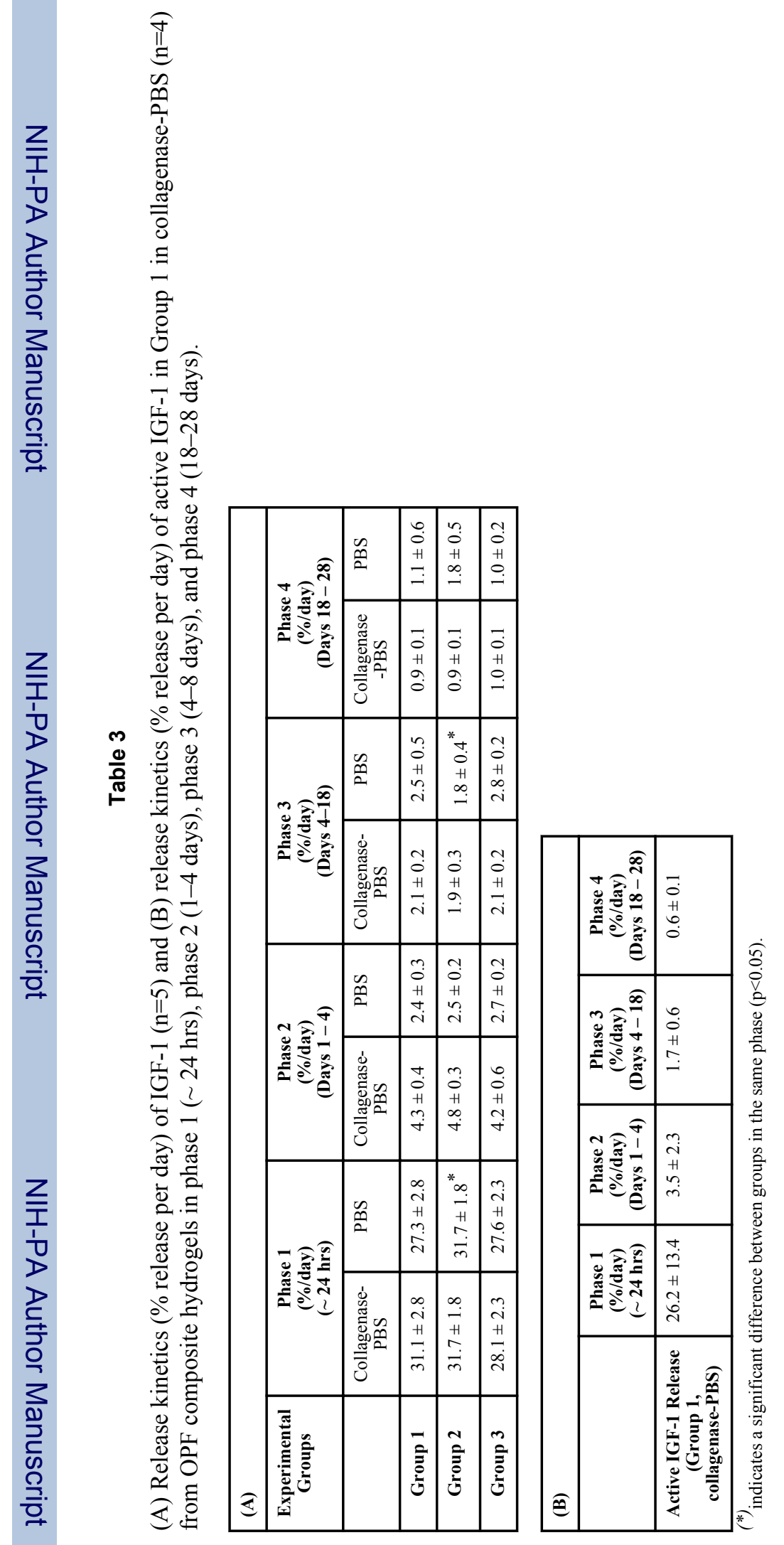




\section{Table 4}

(A) Release kinetics (\% release per day) of TGF- $\gamma 3(\mathrm{n}=5)$ and (B) release kinetics (\% release per day) of active TGF- $\gamma 3(n=4)$ from OPF composite hydrogels in phase $1(\sim 24 \mathrm{hrs})$, phase $2(1-4$ days), phase 3 (4-8 days), and phase 4 (18-28 days).

\begin{tabular}{|c|c|c|c|c|c|c|c|c|}
\hline \multicolumn{9}{|l|}{ (A) } \\
\hline \multirow[t]{2}{*}{$\begin{array}{l}\text { Experimental } \\
\text { Groups }\end{array}$} & \multicolumn{2}{|c|}{$\begin{array}{l}\text { Phase } 1 \\
\text { (\%/day) } \\
\text { ( 24 hrs) }\end{array}$} & \multicolumn{2}{|c|}{$\begin{array}{c}\text { Phase } 2 \\
\text { (\%/day) } \\
\text { (Days 1 - 4) }\end{array}$} & \multicolumn{2}{|c|}{$\begin{array}{l}\text { Phase } 3 \\
\text { (\%/day) } \\
\text { (Days 4-18) }\end{array}$} & \multicolumn{2}{|c|}{$\begin{array}{c}\text { Phase } 4 \\
\text { (\%/day) } \\
\text { (Days 18-28) }\end{array}$} \\
\hline & $\begin{array}{l}\text { Collagenase- } \\
\text { PBS }\end{array}$ & PBS & $\begin{array}{l}\text { Collagenase- } \\
\text { PBS }\end{array}$ & PBS & $\begin{array}{l}\text { Collagenase- } \\
\text { PBS }\end{array}$ & PBS & $\begin{array}{l}\text { Collagenase } \\
\text {-PBS }\end{array}$ & PBS \\
\hline Group 2, 1× & $25.0 \pm 3.1^{*}$ & $28.8 \pm 3.3^{*}$ & $2.5 \pm 0.4$ & $1.7 \pm 0.3$ & $2.1 \pm 0.3$ & $2.1 \pm 0.3$ & $1.3 \pm 0.7$ & $1.2 \pm 0.3$ \\
\hline Group 3, 1× & $17.1 \pm 3.2$ & $19.5 \pm 1.0$ & $6.5 \pm 1.2^{*}$ & $1.7 \pm 0.3$ & $3.1 \pm 0.1^{*}$ & $3.3 \pm 0.4^{*}$ & $1.1 \pm 0.2$ & $0.9 \pm 0.1$ \\
\hline
\end{tabular}

\begin{tabular}{|l|c|c|c|c|}
\hline \multicolumn{5}{|l|}{ (B) } \\
\hline $\begin{array}{c}\text { Experimental } \\
\text { Groups }\end{array}$ & $\begin{array}{c}\text { Phase 1 } \\
\text { (\%/day) } \\
(\sim 24 \text { hrs) }\end{array}$ & $\begin{array}{c}\text { Phase 2 } \\
\text { (\%/day) } \\
\text { (Days 1-4) }\end{array}$ & $\begin{array}{c}\text { Phase 3 } \\
\text { (\%/day) } \\
\text { (Days 4-18) }\end{array}$ & $\begin{array}{c}\text { Phase 4 } \\
\text { (\%/day) } \\
\text { (Days 18-28) }\end{array}$ \\
\hline Group 2, 1× & $25.6 \pm 2.7$ & $1.6 \pm 0.6$ & $1.0 \pm 0.3$ & $1.4 \pm 0.6$ \\
\hline Group 3,1× & $24.4 \pm 5.1$ & $3.1 \pm 0.6^{*}$ & $1.8 \pm 0.1^{*}$ & $1.0 \pm 0.1$ \\
\hline
\end{tabular}

$\left(^{*}\right.$ indicates a significant difference between Group 2 (Gel loading) and Group 3 (GMP loading) in the same phase (p<0.05). 